\title{
THE POLITICS OF LABOUR MIGRATION AND DEMOGRAPHIC CHANGE IN CONTEMPORARY JAPAN
}

BY

ANDREW BISHOP

A Thesis

Submitted to the Victoria University of Wellington In Fulfilment of the Requirements for the Degree of Master of Arts

In Political Science

School of History, Philosophy, Political Science and International Relations

Victoria University of Wellington

2012 


\section{ABSTRACT}

Japan currently faces a demographic crisis resulting from declines in fertility rates and rapid expansion of Japan's elderly population. Public pensions will come under immense strain as shrinking numbers of working age people are forced to support ever more retirees. At the same time, declines in fertility and falling population figures threaten Japan's future economic growth and vitality.

This thesis investigates the relationship between the demographic crisis and Japan's strict immigration policies. Policymakers continue to refuse to allow migration to Japan in order to offset declines in Japan's own working age population. The thesis aims to explain why Japan remains so reluctant to accept migrant workers from abroad, even though this may offer a solution to the problems of demographic decline and depopulation.

I contend that conventional analyses of Japan's immigration policies do not provide adequate explanations for why Japan continues to exclude foreign labourers. Rather, I argue that Japan's attitude must be understood in connection with a binary, "us-and-them" mindset toward foreign countries and communities collectively that exists in Japan's governing and bureaucratic institutions. This mindset is evident in Japan's practical labour policy implementation, and has important cultural and political implications for Japan's public discourses of national identity and interests.

The thesis argues that Japan remains unwilling to accept migrant labourers because of an immigration policy structure that resolutely adheres to an outdated view of migrants as mere units of labour. This overlooks changed global models of migration that prioritise human rights, proactive social integration and strategic selection of migrants. While Japan could ease the effects of depopulation and demographic decline by revising core policy assumptions in order to effectively integrate migrants into the dwindling national workforce, it has so far failed to engage with newer models of migration. My analysis locates Japan's crisis within a wider context of global demographic change and transnational population movement in the twenty-first century. 


\section{TABLE OF CONTENTS}

ACKNOWLEDGEMENTS

4

CHAPTER 1: INTRODUCTION

- The effects of depopulation - is labour migration a viable solution? (12)

- The current situation in Japan - why is depopulation such an urgent problem? (17)

- Japan's reluctance to accept foreigners - an overview (22)

CHAPTER 3: CONVENTIONAL EXPLANATIONS FOR JAPAN'S RELUCTANCE TO ACCEPT FOREIGNERS.

- Outline of literature on the subject of the foreign experience in Japan (29)

- The xenophobia/racism explanation (31)

- The ethnic/cultural homogeneity explanation (34)

CHAPTER 4: AN ALTERNATIVE INTERPRETATION: ISOLATIONISM AND MIGRATION. 38

- The mindset of Japan's policymakers: Japan vs. the global 'other' (38)

- Japan's historical relations with foreigners (39)

- Migrants and Japan's labour market: Barriers to participation (46)

- Cultural and political constraints (51)

- Japan's national concept of identity and relations with the global community (58)

- Labour migration and globalisation (62) 
CHAPTER 5: CONCLUSION.

BIBLIOGRAPHY. 


\section{ACKNOWLEDGEMENTS}

I would like to acknowledge and sincerely thank my academic supervisors, Prof. Xiaoming Huang and Dr. Fiona Barker, for their guidance and encouragement while researching and preparing the material presented in this work. I would also like to thank Dr. Jason Young, Dr. John Leslie, Justin Cargill, Dennis Dawson, Noel Ballantyne, Toni Grace and Lucy Tyndall for their assistance, friendship and advice - I am very grateful for their invaluable support.

I must also extend special thanks to Prof. Eiji Murashima, Prof. Michio Yamaoka, Dr. Eiji Yamamoto and staff of the Graduate School of Asia-Pacific Studies at Waseda University for the opportunity to present and discuss aspects of this research at the GSAPS Workshop for Graduate Students on Security, Economic and Social Issues in East Asia in February 2011. 


\section{CHAPTER 1: INTRODUCTION}

In the early years of the twenty-first century, Japan faces a number of complicated social, cultural and economic problems. Many of these problems pose challenges to core assumptions at the heart of Japan's economic success over the latter half of the twentieth century. Twenty years of stagnant growth rates following the collapse of the 'bubble economy' have undermined Japan's international prestige and reversed many of the economic gains of 'Japan Inc.' and the 'economic miracle'. A similar sense of stagnation afflicts Japan's domestic politics, with a succession of ineffectual governments and prime ministerial resignations hurting public confidence in the nation's democratic institutions. Recent events in northern Japan following the destructive earthquake and tsunami of March 2011 - and the ensuing nuclear crisis at Fukushima - have held back long-awaited indications of economic recovery, depressed public spirits and further diminished public belief in the competence of Japan's powerful bureaucratic state management structure.

One of the most acute and far-reaching social and economic challenges facing Japan in the early twenty-first century is that of demographic change, depopulation and the rapid ageing of Japanese society. The problem is complex: faced with a declining national birth rate, a rapidly-expanding population of senior citizens, and a dwindling labour force, Japan's tax-funded national pension and health schemes may soon be unable to adequately support a 'top-heavy' elderly society. Meanwhile, Japan's overall population figures reached a peak in December 2004 and have fallen consistently ever since then, by as many as 183,000 during 2009 alone. At current rates, Japan's total population is projected to decline by as much as 25 percent by the year 2050 (Statistics Bureau Japan, 2010, pp. 9-10).

Confronted with this situation, Japan's policymakers have been forced to contemplate reform of immigration regulations, thereby allowing greater numbers of legal migrants into Japan as a ready source of labour. This proposition strikes an emotively-charged note in Japan's elite political and bureaucratic circles as well as within mainstream society. Scholars of Japan and casual visitors alike frequently note an apparent absence of foreign residents from Japan's mainstream social milieu. Nevertheless, Japan's current status as a world power rests almost solely upon the pillars of continued economic strength and export production, both of which are threatened by an explosion in the relative number of retirees drawing health 
and pension benefits from a pool of public funds provided by an ever-dwindling number of workers. It is projected now that Japan will be forced to accept a significant influx of working-age people from abroad if it is to avoid a critical shortage of working-age contributors to the national pension system (Harlan, 2010).

Yet, review of immigration and citizenship regulations reveals that Japanese society remains largely closed to foreigners in policy terms. Indeed, many of the policy structures surrounding non-Japanese involvement in Japan's economy and society seem deliberately intended to exclude foreign individuals and communities. As Harlan (2010) states, "Japan has long had deep misgivings about immigration and has tightly controlled the ability of foreigners to live and work [in Japan]".

Many commentators on Japan have proposed that policymakers might potentially lessen the impact of demographic change by legitimising the systematic hiring of migrant workers from abroad. Such a policy would necessitate considerable reform of entrenched social policies and attitudes in order to integrate those migrants into the social and economic fabric of twenty-first century Japan. Considering the extent of present restrictions on the lifestyles and activities of migrants in Japan, questions arise regarding the nature of the transformation that Japanese society would be compelled to undergo to effectively incorporate migrant labour into the national economy. By legitimising hiring from abroad, Japan might aim to offset the harsher economic effects of demographic change and facilitate the provision of social services at a higher level to a greater proportion of its citizens for a longer period. This could be achieved by way of immigration policy reform: by providing greater access to Japan's labour market for migrant workers, policymakers could potentially create an immediate shift in the proportion of working members of society to the elderly and retired. Variations on this idea have become subjects of public attention and debate in Japan in recent times. However, the current direction of Japan's engagement with migrants makes clear that the present class of policymakers are unwilling to consider or even explore the possibility of this kind of reform on a theoretical level, let alone take the legislative steps necessary to bring such a reform into effect. Indeed, many current policymakers continue to resist the very idea of a liberalised migration regime.

Japan is famous internationally as an appealing work destination for foreign language teachers, entertainers and corporate staff. Thousands of highly-skilled foreign workers fill 
niches in the Japanese labour market for which employers are unable to adequately source local labour. Japan also plays host to as many as a quarter of a million undocumented migrant workers and labourers, enabled by a variety of semi-legal or legally ambiguous hiring practices and labour initiatives that meet with the tacit approval of Japan's policymakers and government. Stephen Castles (2004) describes this situation as "a way of managing the contradiction that Japan desperately needs unskilled workers, while public opinion will not accept a labour recruitment policy [...] The authorities have opened various 'side doors' [to migration]. The 'back door' of irregular labour migration also appears to be tolerated" (p. 216). Consequently, it cannot be argued that migrants (both legal and undocumented) are completely denied access to ways of earning a living in Japan. However, legitimising migration on this narrowly restricted scale clearly will not be adequate as a sustainable strategy to resolve Japan's demographic problems. Meanwhile, Japan's strict basic immigration policies remain resolutely in force, and continue to restrict the ability of migrant workers to participate substantively in Japan's labour market.

This work aims to analyse and interpret this impasse and the tensions raised by emerging demographic crisis between socio-economic realities and the desire to maintain social, ethnic, cultural and political status-quo in Japan. The question this research seeks to answer is: Why does Japan resist taking the necessary steps to introduce immigration and citizenship reforms that could help to alleviate the negative economic impact of population decline?

Conventional responses to this question typically refer to well-established theories and assumptions of xenophobia, insularity and cultural intolerance in Japanese society. In contrast, this work will argue that the reasons for Japan's reluctance to accept greater numbers of foreigners can best be explained in a more specific two-part process. The first part identifies an underlying binary, 'us-and-them' mindset held by Japan's policymakers with regard to Japanese interaction with, and involvement in, globalised political and economic systems. Japan's historical isolation created a mythology of cultural, political and ethnic 'uniqueness' that gradually became established as a fixed underlying principle of Japanese public policymaking and governance. Current immigration policies and attitudes to migrants in general extend upon this principle, reinforcing Japan's isolation from modern global communities and systems. By considering the connections between these factors, it can be concluded that Japan's reluctance to reform immigration policies arises from a view of 
global affairs that contrasts Japan with other nations and cultures collectively, and that defines Japanese cultural and national identity in dualistic oppositional terms to other nations and foreign actors on the international stage. An anti-migrant orientation in government legitimises this viewpoint in Japanese mainstream society, and limits the scope of popular support for immigration reform initiatives. This situation creates a mutually-reinforcing negative cycle that acts to further strengthen resistance to migrants in Japan.

The second part of the argument relates to the nature of Japan's engagement with developing transnational migration patterns in the decades since 1945. Since the economic recession of the mid-1970s, labour migration theorists and policymakers have developed a revised set of values and norms intended to negate or minimise the drawbacks of labour migration programmes that appeared as the first postwar age of economic prosperity in the developed world came to an end. These revised values and norms place increased emphasis on the human rights and welfare of migrant labourers, and aim strategically to reduce incentives for undocumented employment and overstaying. In contrast, Japan's policymaking approach to future labour needs adheres closely to conventional postwar assumptions in the international community of the economic and social costs of expanding migrant employment within highly-developed economies. Primarily for this reason, failure to engage substantively with modern globalised communities and systems has caused Japan to persist with outdated restrictive immigration policies.

In general, transnational movement of labour in the globalised era has undergone new academic reinterpretation in conjunction with evolution of the economic and social significance of labour migration for the world economy. In the early twenty-first century, the advent of affordable travel and emerging migrant labour markets markedly changed life prospects and employment opportunities for migrant workers from developing countries. By applying recent theoretical paradigms of transnational labour migration to the context of Japan's current socio-demographic and economic situation, it is possible to see how Japan's policymaking elites have failed to respond to the crisis effectively, instead favouring longestablished conventional wisdom on the subject of immigration reform and migrant employment. This work will argue that policymakers' aversion to conceptual constructions of Japan as part of an increasingly unified and universalised global system explains why they are unable to engage effectively with modern patterns of globalised population movement. 
I have chosen to focus on contemporary Japan in this specific context because it represents a prime case study in societal ageing, demographic decline and the problems of depopulation. Japan is currently the 'oldest' member country in the Organisation for Economic Co-operation and Development (OECD) in terms of elderly as a proportion of overall population (OECD, 2009), and is second only to the Republic of Korea in terms of lowest OECD birth rates (OECD, 2007). As such, Japan's current situation serves as an illustrative model for some of the destructive economic effects of demographic decline. Demographic changes in Japan also provide early indications of the potential outcomes of worldwide demographic change in the twenty-first century. The situation in Japan serves as an excellent reference point for comparison of social policy structures and institutional responses to depopulation around the world. Other highly-developed countries, particularly those in Pacific Asia and Europe, may regard Japan's response to the crisis as a test case in formulating their own immigration policies and measures to combat demographic decline.

From a migration theory perspective, Japan is an example of a country that will require a substantial replacement workforce in the future, as opposed to the supplementary workforce that most twentieth-century international guest worker programmes were intended to provide. This change in the dynamics of labour migration challenges core assumptions of past migration theories, and introduces new variables to the study of liberalised immigration in highly-developed countries. Given the projected outcomes of societal ageing, highly developed economies face new imperatives to develop workable migration solutions, having little alternative but to find some way of supplementing existing workforces in order to support burgeoning elderly populations. Japan's official immigration platform, the Third Basic Plan for Immigration Control (issued in 2005), fails to take any of these kinds of problems or challenges into account, persisting instead with long-established definitions of 'favourable' (that is, highly-skilled or specialised) migrants and 'unfavourable' migrants, built on an underlying policy premise of 'no unskilled workers accepted' (Solidarity Network with Migrants Japan, 2007, p. 10). In the context of discussing Japan's reluctance to implement immigration reforms, this work will address the ongoing sustainability of refusing unskilled migrant workers at a time when Japan's primary industries and social services face critical labour shortages.

Overall, this project aims to explain why Japan continues to refuse to accept migrants in the specific context of demographic decline, depopulation and associated socio-economic 
problems. Many of the concepts and themes that emerge in the course of this discussion imply or directly raise further theoretical and practical questions that deserve in-depth attention and analysis - these include moral and ethical considerations relating to migrant labour, Japan's unwillingness to accept refugees, and other related humanitarian issues. Some of these subjects have important connections and relevance to the central arguments here. However, moral considerations over the sustainability of transnational labour migration or potential immigration reforms in Japan fall outside the scope of this research and will not be discussed in detail. ${ }^{1}$ The emphasis of this work falls instead on developing an understanding of why Japan resists immigration reform, rather than addressing questions of whether Japan should aim to capitalise on the labour of migrant workers. Further, although Japan accepts a very low number of refugees and asylum seekers each year (for reasons closely related to those to be discussed in the body of this work), the aim here will be to analyse immigration policy and engagement with migrants as a targeted response to demographic decline and impending labour shortages. Above all, the central intention is to provide insight into the enigma of why Japan's policymakers seem so reluctant to even consider the concept of reform, and why immigration reform is regarded with so little apparent urgency in Japan at present.

The chapter that follows assesses the current situation in Japan, providing an empirical outline of Japan's demographic problems together with an account of official and public opposition to immigration reform. It addresses the viability of labour migration as a way of alleviating depopulation and demographic decline in Japan, referring to recent sources of information and analysis relevant to Japan's reasons for refusing to engage with foreigners or to accept migrants. Chapter Three provides detailed analysis of common conventional explanations for why Japan continues to resist immigration reform, outlining the central elements of these explanations. I will argue that these conventional explanations are insufficient for the purpose of understanding Japan's current stance on immigration in the context of depopulation and labour shortages.

Chapter Four identifies and discusses the key contributing factors that inform immigration policymaking in Japan. This chapter presents my alternative explanation for why

\footnotetext{
${ }^{1}$ Analyses of immigration policies and global migration based more specifically on humanitarian and moral grounds can be found in Jordan and Duvell (2003), and Juss (2006). Detailed discussion of Japan's refugee policies can be found in Koizumi (1992) and Arakaki (2008).
} 
Japan is reluctant to reform immigration policy, which comprises two central parts, as described above. The first part will address the historical context of Japan's relations with foreigners, the implications of institutional hurdles to access to work and life opportunities for migrants in Japan, and socio-political trends of engagement with migrant communities in Japan. It will identify Japan's essential binary 'us-and-them' worldview, based on the interaction of historical, practical and political factors, and explain why this worldview is a critical contributor to current immigration policies. The second part will explore the interaction of this worldview with the realities of transnational population movement on a global scale, revealing ways in which Japan's present-day immigration policies reflect economic conditions and assumptions of a past era. It will investigate shifts in the economy of population movement from the 'first phase' of postwar temporary labour migration programmes (enacted in the decades immediately following the Second World War, based on neoclassical economic assumptions) to 'second phase' models (based on international norms, globalised values and strategic implementation) that continue to develop in the early years of the twenty-first century. Together, these two parts demonstrate that Japan essentially rejects immigration reform due to continued dominance of policy assumptions that no longer adequately reflect global realities. Overall, I contend that Japan still refuses to accept migrants as a result of crucial failures on the part of policymakers to respond effectively to globalising economic systems and transnational patterns of population movement.

Chapter Five concludes with a brief analysis of the implications of depopulation for policymaking in Japan, a broad comparison of Japan's situation with that of other highlydeveloped countries, and comments on the scholarly implications of this work. By weighing Japan's policy responses against those of other countries, it is possible to gain insight into paths for potential future development of policies that respond effectively to the emerging demands of depopulation on highly-developed economies and societies.

By studying Japan's dilemma - both as a subject in its own right, and as a model and case study for an important social phenomenon affecting highly-developed nations, economies and societies around the world - this work offers new perspectives on depopulation as a global economic and social issue, and as a phenomenon that will profoundly influence future global intercultural relations, politics of identity, immigration policy, development of labour migration networks and patterns of labour migration within the global system. 


\section{CHAPTER 2: LABOUR, DEMOGRAPHY AND JAPANESE SOCIETY}

To provide context for Japan's contemporary immigration policies, it is first necessary to assess current conditions associated with depopulation and demographic decline, as they apply both to the case of Japan and to highly-developed countries more generally. This chapter outlines the reasons why depopulation has become an important economic and social issue for wealthy countries at the turn of the twenty-first century, and will discuss why Japan has become one of the first highly-developed countries to face the more severe consequences of demographic decline. This chapter will also discuss the current state of immigration debates in Japan, outlining the relative extents to which policymakers, the public and influential figures in the national discourse have opposed liberalisation of Japan's restrictive immigration regime.

\section{The effects of depopulation - is labour migration a viable solution?}

The problem of depopulation has become a major area of concern for highlydeveloped countries, and figures prominently in the policymaking and economic projections of mature economies around the world. Studies of the demography of depopulation regard fertility rates as the most important factor in determining rates at which national populations can be expected to grow over time. These contribute to a series of complicated statistical interrelationships that have the potential to bring enormous demographic, political and economic change to many countries at a very rapid pace (Wattenberg, 2004, pp. 6-7). As fertility rates largely govern future population levels, both nationally and globally, it is significant that universal birth rate declines have already come to the attention of demographic analysts. Even the most fertile developing countries have collectively recorded marked drops in fertility rates (defined as the average number of children born to a woman over the course of her lifetime) during the second half of the twentieth century - from a rate greater than 6.1 in 1950 to just above 2.9 in 2005 (Wattenberg, 2004, pp. 5-6). With a replacement level fertility rate of 2.1 , at which national and global populations are maintained at constant levels (d'Addio \& d'Ercole, 2005, p. 12), it is clear that world population levels can be expected to consistently increase for some time to come. Nevertheless, if fertility rates 
continue to decline in accordance with current trends, a world population peak may be reached within just a few decades, and in the cases of a number of highly-developed countries, that peak already appears to have been reached. For this reason, depopulation is an urgent issue for both developed and developing countries.

\section{Figure 1: Trends in total fertility rates}

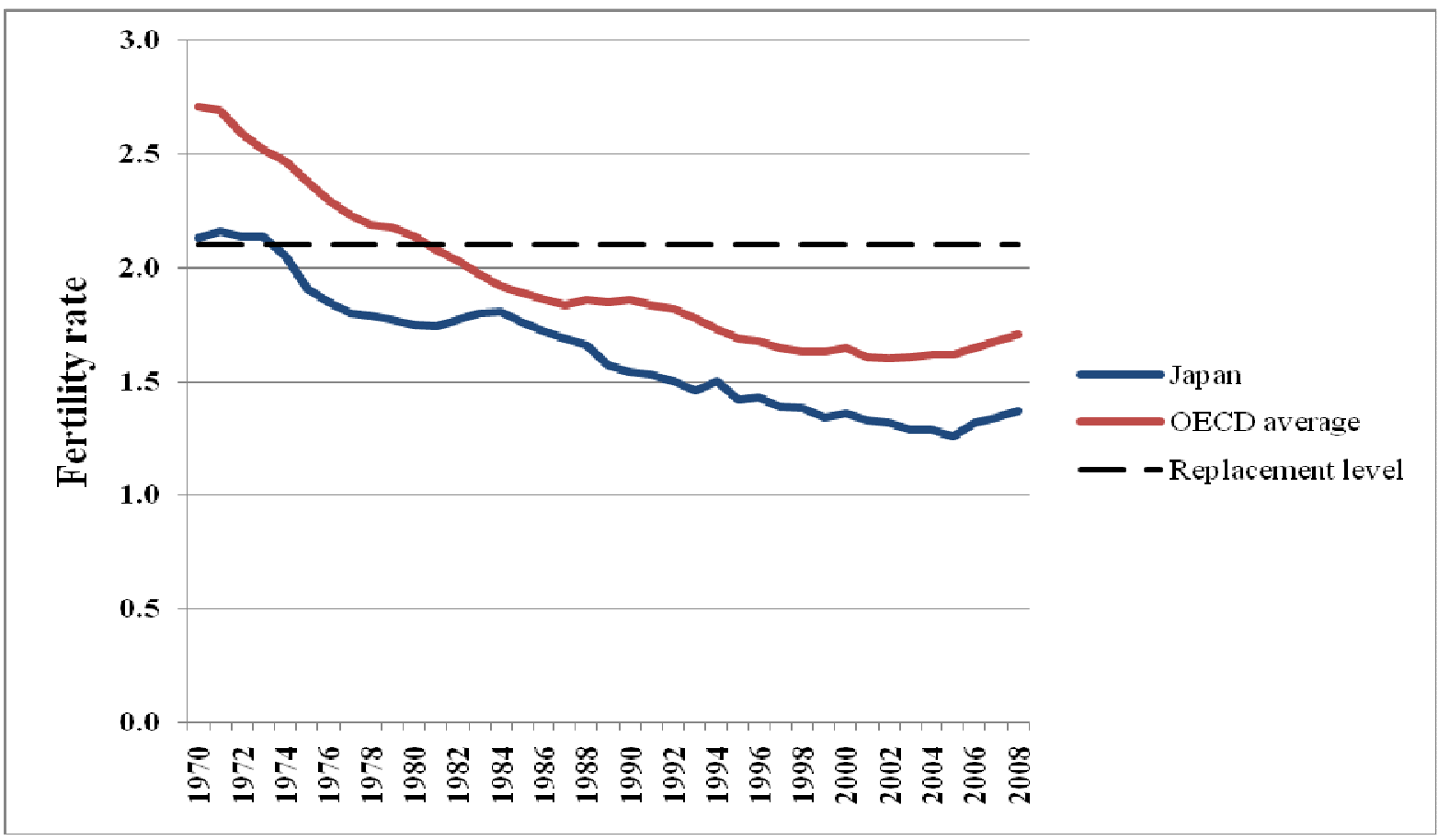

\section{Source: OECD, 2010a}

Depopulation is attributed to a variety of causes within different social and economic contexts. Indeed, the specific demographic conditions associated with depopulation are the subject of some disagreement and debate among analysts (d'Addio \& d'Ercole, 2005, p. 13). Population decline in highly-developed countries has been a subject of particular interest among scholars. These declines are generally associated with combinations of social, cultural and economic factors in mature economies that have resulted in women deciding to delay the point at which they begin to have children. The societal effects of delayed fertility compound across generations, as women who choose to delay having children also necessarily reduce the period of time in which they are physically able to do so - a scenario described as "loss of 
reproductive potential" within society (d'Addio \& d'Ercole, 2005, p. 13). The inevitable result is an upward trend in the average age of society as a whole. The economic and social problems created by fertility decline are further exacerbated by increasing life expectancies, contributing to overall increases in average population age. This is the origin of rapidlyageing and 'hyper-aged' societies, the companion problem typically associated with low fertility rates.

Other explanations for depopulation include the advent of effective contraception, widespread population movements in many countries from rural to urban areas together with corresponding changes in lifestyle, and relative improvements in employment equality and opportunity for women - all of which are again linked directly or indirectly with the tendency among young women to put off having children to a later age than was the case in the past (Wattenberg, 2004, p. 212). Many of these basic problems impact upon the developing world as well, with the global spread of medical knowledge and declining birth rates around the world contributing to a universal growth in elderly populations - perhaps at an even more rapid rate of change than that currently seen in developed countries (The World Bank, 1994, pp. 1-2).

The scale of the depopulation problem faced by highly-developed countries at present is enormous, particularly in economic terms. ${ }^{2}$ As Teitelbaum and Winter (1985) argue, fundamental changes in the age-related demographic make-up of society are "of significance for virtually all aspects of public policy" (pp. 105-106). Economically speaking, the problem is so unprecedented, and the actual implications so difficult to predict, that analysts believe it to be "unlikely that nations facing fewer births, fewer customers, and an ageing problem will show substantial economic growth rates [in the future]" (Wattenberg, 2004, p. 213). As an immediate response, governments have typically offered financial incentives to increase fertility rates and encourage larger families by way of welfare payments, tax credits for parents and revisions to national paid parental leave provisions (Wattenberg, 2004, p. 212). The fundamental weakness of government attempts to promote greater fertility is that, even if these initiatives were to succeed, the benefits of that success would not begin to be seen for a minimum of fifteen years as children gradually reached working age, and would require

\footnotetext{
${ }^{2}$ Wattenberg (2004) broadly defines these countries as a group that enjoys "relative affluence, democratic governance in many forms, and general modernity" (p. 20).
} 
change over the course of entire generations before any meaningful adjustment in the ratio of workers to elderly became evident (Bermingham, 2001, p. 359). ${ }^{3}$

In light of the limited options available to states hoping to actively alleviate depopulation, the incentives for highly-developed countries to consider immigration policy reform as part of a strategy to secure future economic output have become a subject of renewed debate. Immigration liberalisation has some degree of modern precedent, as seen particularly in European countries over the thirty-year 'long boom' period following the conclusion of the Second World War. In those countries, recruitment of temporary labourers from abroad was a critical step toward creating conditions where "migrant labour had become a structural feature of Western European labour markets. [...] Abundant labour with low social costs was a vital factor in the long boom" (Castles, 2000, p. 7). Managed integration of significant numbers of working age migrants into mature labour markets might in principle be an effective way of relieving pressure on declining local working age populations, thereby revitalising economies facing stagnation due to the burden of sustaining disproportionately large populations of senior citizens. By revising immigration regimes in accordance with twenty-first century economic goals, governments of highly-developed countries could increase working population levels and provide immediate economic benefits by boosting domestic labour markets in desperate need of new workers.

Migrant labour can be integrated into a mature economy in several different ways, with varying degrees of long-term value and relative cost to the state. One option is to simply relax immigration regulations to allow a flow of both temporary and permanent migrants to enter, strengthening the workforce and boosting the labour market. Australia, Canada and the United States implemented policies of this type in the years following the Second World War (Castles \& Miller, 1998, pp. 74-76). Alternatively, some form of guest worker programme

\footnotetext{
${ }^{3}$ Some observers now question whether Japan's demographic crisis in particular has now reached a point where immigration reform on anything other than a temporary migration basis would be ineffective as a solution to depopulation and pension funding shortfalls. According to this argument, permitting migrants and their dependants to settle in Japan permanently would simply compound and intensify future demands on the social welfare system as those immigrants retire and begin to draw upon pensions and publicly-funded health services. Bermingham (2001) refers to immigration as "a palliative but not a solution" (p. 360) to developed nations' problems with ageing populations and shortages of workers, arguing that the numbers of migrants required to stabilise a declining working-age population quickly reach unsustainable levels. That is to say, permanent immigration may help to defer population decline and pension funding crises, but is also likely to intensify the unfavourable economic impacts associated with those problems in the future.
} 
can be employed, allowing the state to benefit from the labour of migrant workers without needing to account for the future costs of incorporating those migrants into society on a permanent basis. Guest worker programmes were introduced in the United States during and immediately following the Second World War in the form of the Bracero programme, and in Germany during the 1960s in the guise of a federally-mandated Gastarbeiter guest worker scheme, as well as in other countries (particularly in Europe) facing labour shortages in the same period. Current examples of migrant labour schemes in highly-developed economies (based on varied strategic economic motivations) can be seen in the seasonal migrations of agricultural labourers and live-in caregivers to Canada from the Philippines, Mexico and Caribbean countries (Reed, 2008, pp. 474-476), and in the mass movement of short-term contracted labourers from many countries in Asia to Persian Gulf states such as Saudi Arabia, Kuwait, Bahrain and the United Arab Emirates (Chiswick \& Hatton, 2005, pp. 77-78).

International experience has shown that even a carefully planned and managed flow of labourers into a host society can create significant cultural and political problems. Managed migration programmes create challenges around issues of political representation for migrants within liberal democratic societies, and protection of migrant rights within the framework of host country legal systems. As Zolberg (2000) puts it: "all types of immigrants - including even temporary workers - also constitute a political and cultural presence [within host societies]" (p. 63). Host countries face concerns of temporary migrants establishing a permanent presence, as occurred in Germany at the conclusion of the Gastarbeiter guest worker system in the mid 1970s (Castles, 2000, p. 9). Immigrant communities and networks in host societies have often established permanent sub-communities as a result of visa overstaying, family reunions and the birth of children within that sub-community. This has the effect of creating a distinct class of first-generation migrant residents. In the case of Germany, failure to adequately prepare for this eventuality led to long-term discrimination against migrants within the education system and mainstream labour market, perpetuating social disparity between native and immigrant communities and creating ethnic and class division in German society that has endured to the present day (Castles, 2000, p. 9). Integration of migrants into society can also potentially result in increased migrant political power and demands for greater social and political representation. State support for labour migration also places a moral obligation on host societies in liberal democratic countries to protect migrants from exploitation by employers, adding further complexity and expense to 
the process of establishing migration schemes. Attempts by the state to deny migrants the rights enjoyed by native citizens merely intensify division along ethnic and socio-economic lines, further marginalising migrant communities within host societies.

In these respects, the socio-economic and political effects of labour migration are part of an important nexus of change and development in highly-developed countries. These countries must face a difficult question: Are they willing to tolerate unavoidable political consequences and social change associated with immigration reform in the interests of shoring up economic growth in the present, and of laying groundwork for sustainable economic growth in the future?

\section{The current demographic situation in Japan - why is depopulation such an urgent problem?}

Japan's demographic crisis must be understood as the result of an intertwined relationship between two important social factors: rapid expansion of Japan's elderly population, and consistent decline in the national birth rate. According to Japan's Ministry of Internal Affairs and Communications Statistics Bureau, the eventual outcome of convergence of these two factors is projected to be a 25 percent overall decline in Japan's total population (to 95.2 million people) by 2050 (Statistics Bureau Japan, 2010, p. 10). Japan's response to the situation has been characterised by concern regarding the challenges these problems present to Japan's social structure, culture and national identity. To fully assess the implications of this situation, it is first necessary to investigate the relationship between societal ageing and declining fertility in the specific context of Japan.

Dramatic growth in the number of elderly as a proportion of Japan's population first came to the attention of demographic analysts during the 1980s (Coulmas, 2007, p. 4). At present, Japan's population comprises only 2.6 people of working age (20-65 years) for every person aged over 65 years (OECD, 2009). Upward trends in the age of Japanese society are also linked with general increases in life expectancy, a measure by which Japan already leads among OECD countries at 78-79 years for men and 85 years for women (OECD/Korea Policy Centre, 2009). Japan represents one of the first developed societies to have reached 
'hyper-aged' status, defined as a society in which more than 21 percent of people have reached the age of 65 years or older (Coulmas, 2007, p. 5).

Figure 2: Elderly population as a proportion of total population

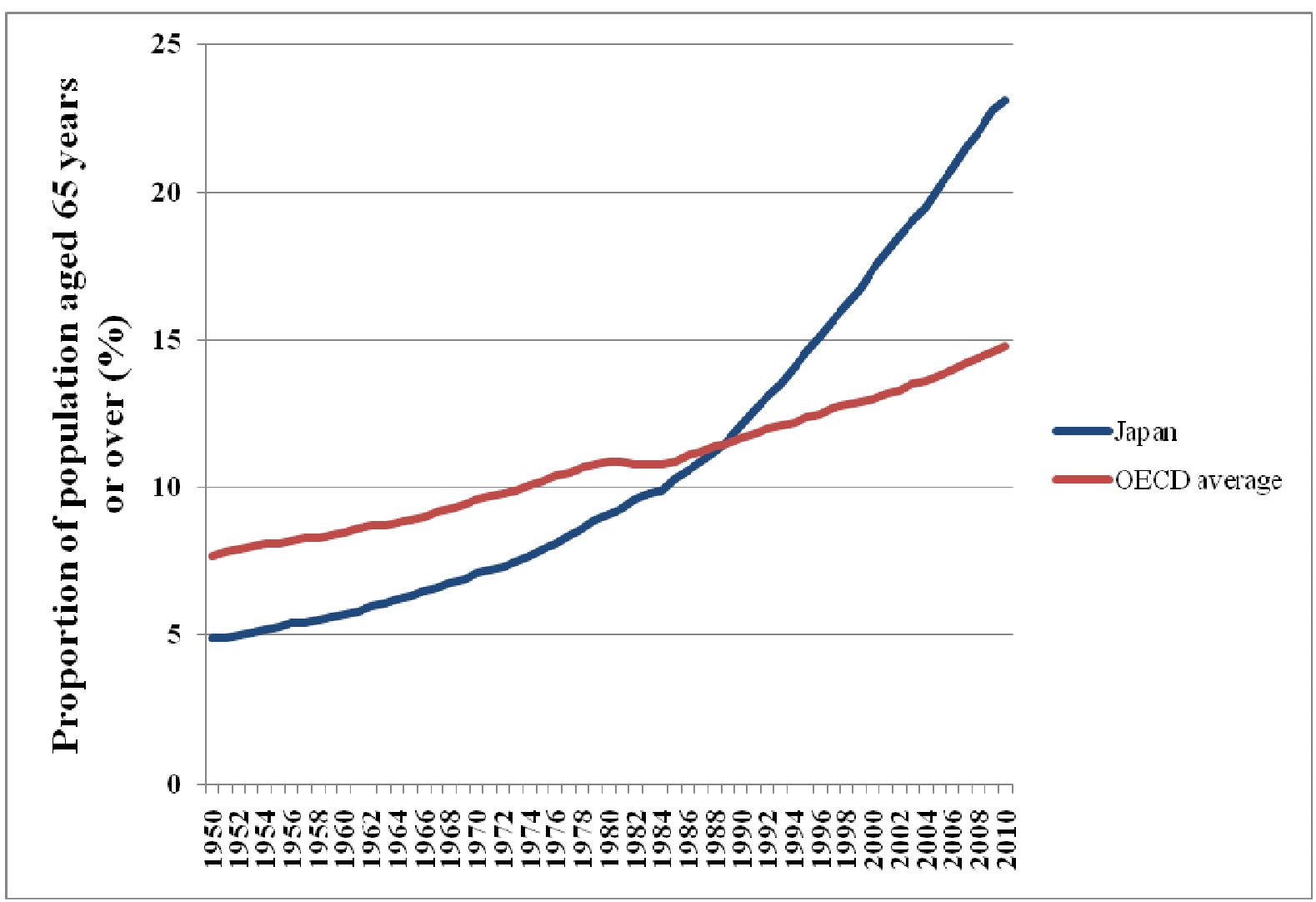

Source: OECD, 2010a

The aging of Japan's population is likely to have an enormous ongoing impact on the nation's entire economy. Sakuragawa and Makino (2007) argue that population decline necessarily infers a decreasing rate of younger workers (aged 20-39 years) to older (aged 4065 years), thereby depressing the wage-earning potential of Japanese workers collectively. This contributes to Japan's general economic underperformance, and creates economic conditions that discourage young Japanese from marrying and having children early, further exacerbating problems of low fertility and population decline (p. 59). According to Sakuragawa and Makino, the negative effect of the present aging workforce trend on growth in Japanese per capita consumption by 2050 will be somewhat greater than 15 percent (p. 70). 
The ability of the state to provide adequate pensions for future retirees has become a source of general concern, given the dramatic boom in numbers of elderly in Japanese society. Many are becoming aware of the huge projected future tax burdens on working-age Japanese necessary to provide adequate pension benefits to a steadily growing elderly population. Japan already suffers from the second-lowest pension replacement rate in the OECD, with new labour market entrants in the 'average earner' category projected to receive pensions of just 34 percent of their working salaries; Japan's old-age dependency ratio, defined by the number of those aged 65 years or older divided by the 'working age' population (aged 20-64 years), has now reached approximately 35 percent (OECD, 2009).

\section{Figure 3: Pensions in Japan - key facts}

\begin{tabular}{l|lll}
\hline Pension & Japan & OECD \\
$\begin{array}{l}\text { replacement rate } \\
\begin{array}{l}\text { Public pension } \\
\text { Spending }\end{array}\end{array}$ & $\begin{array}{l}\text { Low earner (\%) } \\
\text { \%ife expectancy }\end{array}$ & 33.9 & 59.0 \\
& $\begin{array}{l}\text { at birth } \\
\text { at age 65 }\end{array}$ & 8.7 & 71.9 \\
\hline $\begin{array}{l}\text { Population over age } \\
\text { 65 }\end{array}$ & $\begin{array}{l}\text { \% of working age } \\
\text { population }\end{array}$ & 82.4 & 7.2 \\
\hline
\end{tabular}

Adapted from: OECD, 2009

Pension funding shortfalls are becoming a source of intergenerational tension between retirees and younger Japanese workers. The perception among younger workers is that mandatory contributions made to Japan's public pension system today cannot be relied upon to secure their own future income when they reach retirement age. This impression is compounded by a widely-held view that current retirees (and those soon to retire) are being provided with unsustainably generous pension payments (Coulmas, 2007, pp. 13-14). Indeed, Japan's public pension system is already coming under a great deal of strain, being now almost entirely dependent on taxpayer-subsidised 'pay-as-you-go' financing to meet its fiscal obligations. With the effect of consumer price index rises and inflation on the real value of pension payments, together with a growing number of elderly receiving benefits for longer 
periods on average, Japan's pension system is likely to make constantly increasing demands on a dwindling number of taxpayers in the future. Long life expectancies, high old-age dependency ratios and low pension replacement rates pose serious challenges to the ongoing viability of Japan's entire social security structure.

Another important factor in the development of Japan's demographic crisis has been the complicated series of economic and social problems created by significant declines in the national birth rate. The fertility rate in Japan at present is slightly greater than 1.0, significantly below the required rate of 2.1 for overall population replacement $(\mathrm{OECD} / \mathrm{Korea}$ Policy Centre, 2009). National decline in fertility rates is an important development in the larger context of social change in Japan, reflecting acceptance of more inclusive roles for women in the workforce, a general trend toward later marriage among young Japanese people, and an uncertain economic outlook in which many are choosing to delay or forgo having children for financial or career-related reasons.

Changing perceptions of the roles of women have been at the forefront of Japan's economic and social development in the twenty-first century. Despite a relative lack of career opportunity when compared with other industrialised nations, participation of women in the Japanese workforce as a percentage has grown over time; it is now directly comparable with other highly-developed economies (Coulmas, 2007, pp. 50-51). However, despite forming an indispensible component of Japan's modern workforce, women still disproportionately bear the traditional social burden of caring for elderly relatives - a situation popularly known in Japan as kaigo jigoku or 'nursing hell' (Coulmas, 2007, p. 62). The integration of careeroriented women into the Japanese economy - together with law changes facilitating greater gender equality in employment - have produced major downstream effects on fertility, as women apparently now collectively tend to prioritise employment or career development over early marriage and childbearing. That change is reflected in mean ages at first childbirth for Japanese women, which reached 29.7 years by 2009, in comparison with 27.0 years in 1990 and 26.4 years in 1980 (Statistics Bureau Japan, 2010, p. 15). The mean age of first childbirth in Japan now exceeds that of many other OECD countries (d'Addio \& d'Ercole, 2005, p. 13).

Increasing mean ages at first childbirth further suppress the national birth rate by reducing the number of fertile years an average woman can expect after her first childbirth. 
At the same time, social expectations obligate Japanese women to combine care for elderly relatives for extended periods of time with work commitments. The impact of these expectations places a great deal of pressure on Japanese women as a social group, and contributes to falling birth rates. Significant declines in fertility come at a time when Japan is experiencing massive growth in numbers of retirees and increasing life expectancies. This convergence greatly exacerbates the rapidity and severity of demographic decline and societal ageing in Japan.

Changing societal and economic demands on women have brought about corresponding changes in Japanese family structures. Policymakers are now confronted not just with the direct measurable economic effects of population decline, but also by new social disparities arising from the broader economic consequences of falling birth rates and emergence of a 'hyper-aged' society. The advent of a family model in which both married partners work, having delayed marriage and childbearing longer than was traditionally the case in Japanese society, has resulted in a social phenomenon known as kakusa shakai, or the 'gap society' (Coulmas, 2007, p. 14). This expression refers to social inequality and conflict over social redistribution that surrounds the issue of unequal fertility rates currently observed in Japan regionally. Families that choose to delay having children for financial or employment-related reasons are likely to present a massive future burden to the Japanese public pension and welfare system, as Japan comes to rely on family-orientated care and support to offset burgeoning expenditure on social services for the elderly (Ogawa \& Retherford, 1997, p. 70). Declines in fertility rates are more evident in urban than in rural areas, necessitating disproportionate public expenditures in favour of those living in cities. Further, a clear class distinction between fully-employed and part-time or freelance workers has appeared in Japanese society as a consequence of economic recession and a climate of declining employment opportunity and job security (Coulmas, 2007, pp. 14-15). In these ways, the follow-on effects of Japan's demographic problems are beginning to affect other traditional foundations of Japanese society.

As discussed above, fundamental problems lie at the core of concurrent working-age population decline and increasing demand for pensions and social services. Greater numbers of elderly Japanese will come to depend on a pool of public funds that is to be provided by fewer workers nationwide, and expect to do so for periods of time beyond those with which the social security system was originally intended to cope. Policymakers are faced with a 
dilemma; in attempts to keep expenditure on social services at a sustainable level, the government has aimed to minimise social security obligations to the elderly by promoting a return to traditional models of co-residence of elderly parents with their adult children (Ogawa \& Retherford, 1997, p. 76), while encouraging young Japanese to start families earlier and to have more children (d'Addio \& d'Ercole, 2005, p. 47). In the latter case, the government has instituted incentive programmes and increases in childcare benefits for lowto moderate-income families since the 1990s, though the high costs of childcare for working parents in urban areas frequently negate the real financial incentive behind these initiatives. The government has further sought to account for this in part by way of more extensive changes to mandatory parental leave entitlements (Ogawa, Retherford, \& Matsukura, 2009, pp. 63-66).

These social and economic conditions have led influential voices in politics and commerce in Japan, such as the Nippon Keidanren (Japan Business Federation), to begin calling for reform of Japan's immigration laws, arguing in favour of introducing from abroad new working-age contributors to Japan's workforce and tax base. Many of Japan's primary industries and their political advocates support massive increases in migrant numbers to decisively alleviate labour shortages and negative economic effects of depopulation (Nippon Keidanren, 2004). However, in spite of this emerging business discourse in favour of a more youthful and multicultural future for Japanese society, policymakers still refuse to reform immigration regulations that heavily restrict the legitimate use of migrant labour in Japan. As Japan's labour market problems and demographic situation become critical, policymakers seem as unwilling as ever to contemplate opening Japan's borders to benefit from transnational flows of migrant labour.

\section{Japan's reluctance to accept foreigners - an overview}

Considering the gravity of Japan's demographic problems, policymakers and officials have shown remarkable reluctance to even consider immigration reform as a way of alleviating the negative effects of depopulation on Japan's economy and society. Nevertheless, concepts of immigration as a prospective solution to Japan's demographic crisis have become firmly established in public debate and in popular consciousness. Outright resistance to immigration reform is seen within many of Japan's conservative bureaucratic 
institutions, and represents an important policy platform of right-wing and nationalist political organisations in Japan, whose opinions carry significant weight in the nation's political discourse. Due in part to this conflict, successive governments have displayed little interest or enthusiasm for the task of immigration reform.

Japan has experimented with labour migration to a limited extent in the past by attracting specific migrants to Japan based on ethnic qualifications, though the economic conditions that led to that experiment were quite different to those of the current demographic crisis. Beginning in the mid 1980s, a wave of migrants began to enter Japan as part of an initiative by Prime Minister Yasuhiro Nakasone's administration to rejuvenate the Japanese labour market in the midst of booming industrial expansion and economic growth. The constituents of this influx were Nikkeijin - migrants of Japanese ethnic descent from Latin American countries, for whom labour laws were modified in 1990 in order to encourage a wave of 'return' labour migration (Coulmas, 2007, pp. 116-117). It was thought by Japan's Ministry of Health, Labour and Welfare that migrants with Japanese ethnic heritage would be more compatible with Japan's social and cultural structures, though many of these migrants spoke no Japanese and had little in common with local communities beyond their own ancestry (Shipper, 2008, p. 38). Efforts were also made to encourage international students to undertake study in Japan, resulting in a dramatic upswing in numbers of foreign students living in Japan by the late 1980s (Coulmas, 2007, p. 116). However, these limited migration initiatives were not accompanied by further reform of Japan's immigration policies. By aiming to restrict immigration opportunities to very specific groups of migrants (specifically those with highly specialised trade or academic backgrounds, or those with Japanese ethnic roots), immigration regulations at that time effectively continued Japan's long-established social policies of isolation and exclusion of foreign nationals.

Since the 1980s, immigration regulations have become a prominent topic of debate in the public sphere and popular media in Japan, where the implications of immigration reform have been most openly discussed. According to a public survey conducted by the Asahi Shimbun newspaper in 2001, a majority of respondents agreed that Japan should consider accepting unskilled labour immigration on a conditional basis, with notably higher levels of support registered among younger respondents - more than 70 percent of those polled between the ages of 20 years and 50 years supported increased numbers of unskilled labour migrants to Japan, whereas support among those older than 60 years barely reached 50 
percent (Ohno, 2001). However, lingering public scepticism reflected uncertainty over anticipated negative effects of an influx of foreigners into Japanese society; the survey revealed fears that "allowing foreign workers in will lead to a deterioration in Japanese working conditions and stir up trouble within the community at large" (Ohno, 2001), though a total of 64 percent of respondents nevertheless supported local and national governments providing comprehensive social services for migrant workers. Significantly, more than 60 percent also responded positively to the idea of instituting voting rights for long-term foreign residents in Japan - a change that would bring a radical departure from previous foreign residency policies.

However, since 2001, enthusiasm for migrant workers in Japan appears to have declined, perhaps as a result of enduring recession and increasing unemployment. A series of public opinion polls conducted by Japan's Cabinet Office found that overall opposition to migrant workers entering Japan had grown from 49.2 percent in 2000 to 70.7 percent in 2004 (Shipper, 2008, p. 180). This conclusion was supported by another Asahi Shimbun poll conducted in June 2010. By surveying attitudes to immigration as a means of "maintaining economic vitality", the Asahi poll found that 65 percent of respondents now opposed labour migration, with only 26 percent in support (Harlan, 2010). In spite of recent public scepticism, calls for immigration reform have multiplied, as noted in the national Daily Yomiuri newspaper (Sakanaka, 2010). Commentators have persisted in calling for bold reform of immigration regulations, arguing that “the only long-term solution for alleviating the nation's population crisis is a government policy of accepting immigrants" (Sakanaka, 2010). Overall, while debate over Japan's demographic problems has gained greater attention and urgency, concepts of labour migration as a feasible response to the demographic crisis have fluctuated in terms of public support. Nevertheless, the essence of immigration debate has evolved over time from a discussion of whether migrant individuals and communities have any role to play in Japanese society at all, to one focusing on whether migrants could be a viable source of labour on which Japan's labour market might depend in the future (Coulmas, 2007, p. 119).

Japanese business lobby groups and associations have largely promoted the view that immigration reform is acceptable and economically inevitable. For instance, the Nippon Keidanren publicly supports labour migration on economic grounds, stating that migration was necessary to bring "the dynamism of diversity into Japan from outside" and criticising the fact that "accepting non-Japanese workers into the country is not yet being considered as 
a viable option for filling this gap" (Nippon Keidanren, 2004). Seemingly regardless of pressures from industry and the public, Japan's national government has shown considerable reluctance to acknowledge these views. Little substantive change has been evident in government policy surrounding the subject since the Immigration Control Law (revised in 1982 as the Immigration Control and Refugee Recognition Act) took effect in October 1951 (Taberner, 2008). Attempts have certainly been made by some prominent public figures to bring the matter of immigration reform to the attention of policymakers. A group of Liberal Democratic Party (LDP) lawmakers led by former party Secretary General Hidenao Nakagawa announced a proposal in 2008 for Japan to accept ten million labour migrants by the year 2050, allowing both workers and their families to reside permanently in Japan and mandating the creation of a centralised immigration regulatory body - these represented unprecedented steps toward reform. However, this proposal was not implemented before the LDP's defeat in the 2009 general election. As a result, LDP lawmakers were subjected to criticism over the confused state of Japan's immigration priorities, in light of a series of immigration crackdowns over the previous decade targeting young families that had in many cases successfully integrated into Japanese society. The LDP faced accusations that Japan was in the process of permanently deporting the same groups of people that Nakagawa proposed to attract as part of the reform proposal (Clark, 2009).

The rise to power of the Democratic Party of Japan (DPJ) in the 2009 general election after more than fifty years of LDP rule renewed hope for progressive development in migrant employment regulations and greater openness to foreigners in the Japanese labour market. During the election campaign, the central DPJ social policy platform essentially matched conservative LDP-era policies of more extensive taxpayer-funded childcare subsidy programmes for prospective parents (Kelly, 2009). However, in June 2010 Prime Minister Naoto Kan's government announced a new series of immigration reform proposals intended to attract migrants, with a goal of doubling the number of highly-skilled migrant workers in Japan by the year 2020 (Harlan, 2010). This proposal met with criticism for operating in conjunction with revisions to immigration and residency laws (to take effect in 2012) that consolidate Japan's locally-administered alien registration card system into a single national database overseen by Japan's Ministry of Justice, engendering fears of future system-wide clampdowns on foreign residency in Japan and further isolation and marginalisation of resident foreign communities (Eubank, 2010). As these examples illustrate, forward-looking 
official attempts to reform Japan's immigration policies have been accompanied by legal provisions intended to restrict social integration of migrants. Equally, reform attempts of the past have revealed deep misgivings among policymakers regarding the social consequences of allowing greater numbers of foreign workers into Japan on a permanent basis. Overall, these mixed messages have created uncertainty over the seriousness with which political actors in Japan regard immigration reform and demographic problems.

The approach of Japan's bureaucratic agencies (such as the Ministry of Justice, Ministry of Foreign Affairs and National Police Agency, among others) to this issue has been to consistently and deliberately conflate foreign communities and individuals with images of crime in Japanese society. Many observers have noted a tendency of these agencies to publicise foreign crime statistics out of their demographic and social contexts in order to promote an impression of migrants as threats to society. Shipper (2008) points to analysis of National Police Agency crime statistics from the period 1993-2005 that suggest that while the overall number of criminal offenses committed by foreigners in Japan increased over that period, many offenses could be attributed to breaches of immigration and alien registration regulations (which are not applicable to Japanese nationals), and that official statistical analyses failed to acknowledge the multiple offences that necessarily result from overstaying or incorrect registration in the alien registration system (pp. 160-161).

Prominent political figures have persisted in characterising foreign residents of Japan as criminals - a well-known example being the incumbent Governor of Tokyo Shintaro Ishihara, noted for publicly referring to immigrant communities using the derogatory term sankokujin (literally 'third-country persons', in the sense that they belong neither in Japan nor in their native countries), and for suggesting that foreign residents in Japan could be expected to riot in the event of a major earthquake (Larimer, 2000). Similarly, LDP faction leader, former Construction Minister and former Director-General of the Management and Coordination Agency Takami Eto publicly stated in 2003 that "in [this] country, there are one million illegal foreigners, who are committing robbery and murder" (Shipper, 2008, p. 163). Data for that year indicated that foreigners of all nationalities were responsible for 145 robberies and 16 murders, while Japanese nationals were reported to have committed 4,698 robberies and 1,456 murders in the same period. Total numbers of illegal foreigners in Japan are estimated to have not exceeded 300,000 at any given time, in contrast to Eto's claims (Shipper, 2008, pp. 159, 163). The promotion of negative migrant stereotypes by public 
servants and politicians in public debate has a powerful effect in moving immigration policy in a conservative direction, deterring progressive lawmakers from pressing more insistently for the kind of liberal reform seen in the Nakagawa and Kan immigration proposals.

Outside government circles, other conservative contributors to Japan's political discourse openly express objections to liberalising Japan's immigration regulations and support bureaucratic resistance to immigration reform proposals. Nationalist and conservative groups in Japan endorse arguments that foreign residents are responsible for many social problems, and that migrants represent a threat to Japan's social harmony and stability. Opposition to immigration and foreign residence in Japan originates both from longestablished ultranationalist political groups known in Japanese as uyoku dantai, and from a recent wave of right-wing movements (known as the 'Net right') organised around internetbased social networking sites (Fackler, 2010). The views of some of these groups have enjoyed considerable support within the Diet, as nationalist political organisations exert considerable influence over Japan's policymaking processes. ${ }^{4}$ Uyoku dantai groups also wield power over lawmakers using intimidation and pressure tactics, making both veiled and overt threats to those they perceive as too progressive on issues of national identity and culture (Shibuichi, 2007). The correlation between nationalist ideology and legislative power has entrenched blocs of opposition to immigration reform within Japan's governing institutions that obstruct the government from moving toward substantial immigration reform. Though nationalist groups vary in the specifics of their views regarding Japan's engagement with other countries and resident migrant communities, they typically share a broad antiimmigration position - for example, 'Net right' groups such as the Zaitokukai (an abbreviation of 'Citizens Group That Will Not Forgive Special Privileges For Koreans In Japan') campaign against the rights of long-term immigrant communities in Japan (Fackler, 2010). These groups promote a highly-visible counter-position to pro-immigration voices in public debate, and provide ostensible popular legitimacy to those in government and the bureaucracy who oppose immigration reform on racially-motivated or nationalistic grounds.

\footnotetext{
${ }^{4}$ Recognising the extent of conservative political power in Japan, Szymkowiak and Steinhoff (1995) depict the origins of modern right-wing ideology on contemporary mainstream Japanese politics as "a subsurface alliance [that] developed between radical right and centre-right coalition in power [immediately after the Second World War], which later coalesced into the Liberal Democratic Party" (p. 269).
} 
In summary, immigration reform and the integration of migrants into Japanese society is a controversial topic in Japan's public discourse. While proponents of immigration reform enjoy qualified moral support from mainstream society, powerful interest groups in Japan's government, legislature and civil society oppose real reform and favour a policy of maintaining status-quo in immigration policy, regardless of whether or not that policy may be sustainable for the country's economic and demographic future. 


\section{CHAPTER 3: CONVENTIONAL EXPLANATIONS FOR JAPAN'S RELUCTANCE TO ACCEPT FOREIGNERS}

Japan's immigration policies have received considerable attention from scholars and media, as the scale of the depopulation problem in Japan has become more widely recognised. Discussions of the subject purport to identify specific core reasons that explain the origins of current Japanese policy in simple terms. These typically revolve around issues of race, intolerance, xenophobia, cultural 'uniqueness', and assumptions of monoethnic and monocultural social structures in contemporary Japan. In contrast, my explanation for Japan's immigration policies locates Japan's cultural milieu, traditions and governing ideology within a wider context of worldwide development and globalisation. The purpose of this chapter is to outline the bases of conventional arguments for Japan's reluctance to liberalise immigration regulations, and to demonstrate that these are not sufficient explanations for the motivations behind Japan's ongoing cultural isolationism. Most importantly, this chapter is intended to differentiate between conventional inwardly-focused Japan-centric explanations for reluctance to accept migrants, and a broader, more contextual globalised explanation for Japan's immigration policies, for which I make the case in Chapter Four.

\section{Outline of literature on the subject of the foreign experience in Japan}

Japan's reluctance to accept large-scale migration of foreigners into Japan - and restriction of migrants living in Japan - has already attracted a great deal of academic and popular attention. Much literature has aimed to analyse implications and predict outcomes of Japan's demographic problems. Indeed, since the reopening of Japan to foreign trade and political influence during the Tokugawa era, both foreign and Japanese observers have taken interest in Japan's relationship with the wider world. Contradictions that inform Japan's foreign relations are a part of the perennial attraction of Japan as a subject for political and social analysis. Investigation of Japan's demographic crisis continues in that tradition, focusing on an apparent policy struggle between responding to a demographic crisis that threatens the future prosperity and economic viability of Japan, and a seemingly compulsive desire to keep the world at arm's length, even though the labour contributions of migrants 
may prove essential in keeping Japan's economy afloat. In short, modern Japan poses a fascinating theoretical conundrum for academic analysts and popular commentators alike. A body of literature forms the basic framework used as a reference to define Japan's primary social policy problem of the twenty-first century - that is, the response to demographic change and population decline.

A tradition of foreign discussion of Japan's culture and customs was established during the Meiji era, with writers such as Lafcadio Hearn in Glimpses of Unfamiliar Japan (1894) and Basil Hall Chamberlain in Things Japanese (1890) providing early detailed insight into the structure and functions of Japanese society and the reception of foreigners in Japan's social order. In the twentieth century, a landmark work dealing with Japan's social relations was Ruth Benedict's The Chrysanthemum and the Sword (1946). Though produced without the benefit of firsthand experience of research in Japan or access to many primary resources (pp. 5-8), Benedict's attempts to understand the motivations behind Japanese behaviour and customs set a precedent for postwar anthropological study of Japan. The groundbreaking aspect of Benedict's work was identification of Japan's social patterns, allowing readers an insight into the workings of Japanese society and culture. Analyses of this type multiplied with the later emergence of interest in Japan's corporate business models, with many researchers and authors such as Richard T. Pascale and Anthony G. Athos in The Art of Japanese Management (1981) and Ezra F. Vogel in Japan as Number One (1979) aiming to identify the paradigms of social organisation, bureaucratic governance and corporate structure that allowed for Japan's 'economic miracle' in the 1970s and 1980s.

Contemporary works have aimed to re-examine Japan's customs and culture in a twenty-first century context. A common purpose of these efforts has been to identify particular features of the Japanese outlook that explain the negative reception of migrants in Japanese society - or as Kerr (2001) puts it, the tendency for foreigners to be "kept at arm's length" (p. 351). This contrast poses a particularly interesting puzzle for foreign observers, as Japan is also internationally famous for a culture of hospitality, leaving many short-term visitors to Japan with very positive impressions of Japanese society. One common conclusion is that institutionalised racist beliefs and assumptions of cultural superiority explain Japan's unwillingness to accept migrants, and desire to keep foreign influence out of domestic politics and society; this position is argued by Reischauer (1988) and Shipper (2008), among others. Another important interpretation - as argued by Young (1983), Buckley (1990) and 
others - revolves around belief in the nature of Japan as a 'homogenous society'; that is, the idea that Japan is uniquely constructed in political and social terms from a monoethnic foundation based on kinship and 'unique' thought patterns determined by nuances of Japanese language, culture and expression. Scholars such as Van Wolferen (1989), Lie (2001) and Chung (2010) have argued against the existence of such a social model in Japan, and much debate continues around theories of 'social homogeneity'. In order to understand some of the weaknesses and inadequacies of conventional interpretations of demographic change and immigration reform in contemporary Japan, it is necessary to look at these two essential schools of thought in more detail. The purpose of this chapter is to explain the ways in which assertions of 'social homogeneity' compare and contrast with more straightforward concepts of racial and cultural intolerance.

\section{The xenophobia/racism explanation}

The most commonly cited explanations for why Japan so thoroughly restricts opportunities for migrants are based on arguments of racism, xenophobia, institutionalised discrimination and assumptions of cultural superiority in Japanese culture. This interpretation acknowledges the surface appearance of the immigration debate in Japan; that is to say, Japan's unwillingness to engage with migrants socially or politically suggests straightforward intolerance or disdain for foreign people, cultures and customs. Some scholars note that this reaction perhaps reflects the general scarcity of opportunities for Japanese people outside the major cities to interact with foreign residents; as Reischauer (1988) points out, "Most Japanese go for years or even their whole lives without having any significant contact with a foreigner" (p. 390). Further, minimal levels of interpersonal contact or intercultural understanding contribute to widespread disinterest in engaging with foreigners (p. 392). Advocates of the racism argument cite this state of affairs as evidence in itself for why Japan refuses to accept migrants.

The racism argument emphasises many aspects of Japanese social life that imply disapproval or discrimination against foreigners. A particular subject of interest is the way in which foreign ethnicity and cultural identity is dealt with by Japanese citizenship and residency regulations. One commonly-noted example is the Japanese local government alien registration card system that requires non-citizens to carry an identity card bearing the 
holder's image, name, date of birth, home address, place of employment and other personal information whenever out in public. Foreign residents of Japan face arrest or fines if this document cannot be produced when requested by police. Proponents of the racism argument highlight incidents of harassment and alleged ethnic profiling on the part of Japanese police, where residents of 'non-Japanese' appearance frequently undergo intrusive questioning or searches by police (Arudou, 2010b). Other references to discrimination include the status of long-term multigenerational residents of Japan, especially those of Korean or Chinese ethnic descent, who must openly renounce their native cultural ties and identity in order to be recognised as Japanese citizens. These examples are intended to draw attention to rigid distinctions in Japanese laws and society between 'foreign' and 'native' in definitions of citizenship and ethnicity. Official tolerance of 'no foreigner' policies and signs in places of business are presented as evidence of the entrenchment of xenophobic attitudes in Japanese society - for example, in relation to ethnically-exclusive golf club memberships (Clark, 2009), and to discrimination in housing and apartment rentals (Arudou, 2010b).

Commentators on the subject of discrimination against foreigners in Japanese society frequently refer to the concept and history of dejima (literally 'an outside island') to articulate the attitude of government agencies to the presence of foreign communities in Japan, and to characterise the relationship between foreigners and mainstream society. The dejima reference can be traced to the early years of officially-sanctioned trading between Japanese subjects and foreign merchants in Nagasaki, where business transactions were geographically restricted to a single island within the harbour basin. The purpose of this outpost was to insulate subjects on the mainland from foreign influence, which was feared as a threat to the authority of the Tokugawa shogunate (Kazui \& Videen, 1982). Proponents of the racism argument now directly link the historical policies that gave rise to a physical dejima in Nagasaki, and modern-day policies that metaphorically isolate Japanese society from foreign intrusion in a similar manner; as Douglass and Roberts (2003) put it, "the policy of government and the practice of society has been to pretend that immigration was not occurring and to require foreigners either to live in officially-designated enclaves or otherwise to be contained in specific neighbourhoods" (p. 11). Kerr (2001) takes this argument further by stating, "Modern-day rules that restrict foreigners to certain discrete corners of Japanese society and keep them out of the mainstream can be traced to dejima. And the dream of a physical dejima for foreigners has never faded. [...] Many national and 
local development plans [have] called for getting all the foreigners to move into special apartment buildings designed just for them - often on landfill islands" (p. 344).

Lie (2001) claims that "new foreign workers constituted a problem insofar as they posed a potential, and largely symbolic, threat to Japanese society due to their racialisation [...] [meaning] the process by which a group comes to be marked by its physical and cultural distinctiveness" (p. 18). The racism argument states that this view of migrants as a threat has led Japan's policymakers to flawed conclusions regarding the cultural makeup of their own society. Difficulties in determining precise definitions of a difference between Japanese ethnicity and Japanese citizenship have resulted in policy structures that do not clearly define 'Japanese' status as recognised by the government. For instance, Arudou (2010a) refers to the lack of an option for naturalised Japanese citizens in the 2010 Japanese national census to indicate ethnicity and citizenship status separately. It is argued that Japan's social policies do not take multiethnic or multicultural identities into account when determining a citizen's relationship with the state. Put another way, this argument states that governing structures in Japan are ill-equipped at present to cope with an eventuality where portions of Japan's population might self-identify with multiple ethnic, cultural and linguistic backgrounds. The compulsion to resist reform, it is argued, stems largely from the current social acceptability of excluding migrants of non-Japanese ethnic background from rights and privileges enjoyed by citizens. This allows the government to avoid creating institutional policy frameworks that take multicultural identities into account. Arudou (2010a) concludes, "Japan's identity is currently based on the ideals of cultural and even racial purity. Why would one dare to collect official data that would undermine that?"

According to this argument, the inevitable outcomes of these conditions are immigration policies defined by preoccupation with the ethnic and cultural characteristics of 'non-Japanese' residents of Japan - that is, a policy structure defined by racial intolerance. For instance, Befu and Manabe (1990) regard popular discussion of ethnic diversity in mass culture and literature as emblematic of a mainstream Japanese identity defined exclusively in ethnic terms. They assert that ethnicity is popularly believed to operate "as a mechanism for maintaining the cultural boundary between Japanese and non-Japanese" (p. 126). Shipper (2008) characterises Japan's current immigration policies as based on treating foreigners "unpaternalistically [...] and categorises them hierarchically by race (or nationality)" (p. 25), emphasising an institutional lack of coherent integration strategies for migrants in Japanese 
society. Similarly, Coulmas (2007) highlights the effects of exclusionary immigration policies on migrants' relations with society and the state, arguing that many "have qualms about their status as 'members of the Japanese society' [...] This sentiment is shared by many, foreigners and Japanese alike, and forms one of the major intangible obstacles to increasing immigration" (p. 116). These arguments sample an overall school of thought that connects Japanese reluctance to accept migrants with racism, xenophobia and cultural insularity. Advocates of the racism argument opt to focus attention on intolerance in contemporary Japan, which purportedly "seems happy in its cultural isolation, and still thinks it can survive without a sensible immigration policy" (Clark, 2009).

\section{The ethnic/cultural homogeneity explanation}

The second typical explanation for Japan's reluctance to accept migrants is connected with perceptions of Japan's supposedly monoethnic and monocultural society. These ideas are usually collectively referred to as 'social homogeneity'. The core of this argument, as advocated by Reischauer (1988), Buckley (1990) and Young (1983), is that Japan is an isolated example of social and ethnic sameness to an extent unseen elsewhere among the world's developed nations. Refusal to allow migrants into Japan on a long-term basis in significant numbers consequently reflects a desire to maintain Japan's social uniformity, and to avoid disruption to the institutions and policies that developed to serve a homogenous society. Douglass and Roberts (2003), Lie (2001), Chung (2010) and others refute this argument on a conceptual and empirical basis, pointing to evidence that Japan is not monoethnic and monocultural in character. These scholars refer to significant long-term resident communities of non-Japanese extraction, return migrants of Japanese descent, and other minority groups (such as long-term resident Korean and Chinese communities) in the overall makeup of modern Japanese society. Debate over the concept of social homogeneity aids in clarifying the structure of contemporary Japanese society to some extent, but arguably does not provide an adequate mechanism for understanding the deeper motivations Japan's unwillingness to accept immigration reform.

The concept of social homogeneity in Japan has served as a focal point for many foreign observers and scholars of social relations in Japan. Reischauer (1988) states, "the Japanese today are the most thoroughly unified and culturally homogenous large bloc of 
people in the world, with the possible exception of the North Chinese" (p. 33). Young (1983) concurs: "Local, regional, and occupational diversity exists, but the nation is intrinsically far more unified that any other industrial nation" (p. 71). Based on these assumptions, proponents of the social homogeneity argument interpret Japanese society in terms of monoethnicity and monoculturalism.

Advocates of the social homogeneity explanation refer to Japan's past immigration record, either to reaffirm the validity of anti-immigration arguments or to disavow social homogeneity as a deliberately constructed myth (Douglass \& Roberts, 2003). Put another way, the centrality of the social homogeneity concept effectively frames much debate over immigration reform. In particular, the extent of past migration to Japan is a fervently disputed topic; some scholars openly assert that Japan has never undergone any period of migrant inflow at all. Sassen (1994) states, "Japan has never had immigration, though it has a history, even if at times brief, of forced labour recruitment, colonisation, and emigration. It lacks a belief in the positive contributions of immigration. The concept immigration did not exist in its law on the entry and exit of aliens" (p. 62). Others refute these assumptions, pointing to historical evidence of foreign influence in Japan's arts, culture and language, and favouring more nuanced interpretations of Japan's migration history. Douglass and Roberts (2003) emphasise the ideological underpinnings of 'immigration denial' and maintain that migrants have been important actors in the development of Japan's society, arguing that the immigration debate is manipulated to entrench fears of "an assault on the racial purity of Japan" (p. 11). Chung (2010) argues that while Japan recognises an essential need for immigration reform, policymakers have shown far greater interest in punishing visa violations and expelling overstaying immigrants than in creating sustainable policy frameworks for migrant integration (p. 144). These exchanges share theories of social homogeneity as a conceptual hub around which debate over importance of migrants to Japan's culture and society revolves.

A considerable volume of academic literature does refute the concept of social homogeneity in Japan. As Clammer (2001) argues, "Japan empirically has always been a diverse society, differentiated by region, dialect, local economies and cultures, [and] by religious pluralism" (p. 20). Similarly, Lie (2001) states: "The fundamental forces of modern Japanese history - state-making, colonial expansion, and capitalist industrialisation engendered ethnic heterogeneity. To speak of modern Japan is to speak of multiethnic Japan" 
(p. 83). These scholars argue that Japan's long history of regional individuality disproves the social homogeneity argument. Instead, it is argued that Japan's outward appearance of uniformity and social sameness is a consequence of cultural and political pressure that pushes examples of diversity to the margins of society. Elaborating on this point, Kerr (2001) refers to Japan's monocultural ethos as a psychological construction: "[This ethos] is in the mind. It's the emotional consequence of Japan's rigid systems, which bind individuals and keep out the fresh air of new ideas from abroad" (p. 354).

Conventional analyses of Japan's reluctance to accept migrants are limited in the extent to which they explain the reasons behind Japan's current reluctance to accept foreigners, concentrating instead on surface characteristics of the immigration debate and social attitudes toward migrants. The purpose of the chapter that follows is to reinterpret these arguments in a new context, with a specific focus on explaining on a structural level why Japan persists with exclusionary social and political policies in the face of demographic change. My argument is based in some instances on alternative interpretations of evidence used to support the conventional opinions described above. However, conventional arguments tend to overemphasise one side or other of the social divide between migrants and mainstream Japan. The racism argument implicitly takes the side of foreign residents of Japan, focusing on denials of fair representation, basic human rights and the marginalisation of migrants based primarily on qualifications of race or identity. Conversely, the social homogeneity argument highlights supposed cultural requirements for recognition within Japan's social structure, concentrating on an implied incompatibility of migrants with Japanese society as a unified entity; that is to say, proponents of this argument are preoccupied by whether there is 'room' for migrants in Japanese society, as a response to the question of why Japan's policymakers reject appeals for immigration reform. In reality, both sides of the dichotomy are relevant to the immigration debate in Japan. However, I contend that both arguments ultimately interpret immigration issues in Japan in terms that are too narrow. Though it may be true that migrants face social hostility based on racial prejudice, this does not fully explain why Japan is unwilling to accommodate foreigners for economic reasons; similarly, evaluating Japan's history of diversity by itself does little to explain policymakers' views regarding the importance of Japan's demographic problems as measured against impulses to protect the status-quo in Japan's social structures. 
In contrast, my analysis locates conventional models of Japanese identity within a wider context of globalised labour migration. By questioning policymakers' core assumptions regarding immigration policy, migrant integration and the effects of migration on the character of Japanese society and politics, the next chapter aims to explain the reasons behind current policy structures that neither effectively address Japan's looming demographic crisis, nor reform the difficult conditions faced by migrants upon whom Japan's future prosperity may depend. 


\section{CHAPTER 4: AN ALTERNATIVE INTERPRETATION: ISOLATIONISM AND MIGRATION}

The purpose of this chapter is to outline and defend an alternative explanation for Japan's persistence with highly restrictive immigration policies in the face of societal ageing and demographic decline. Evidence for Japan's overall outlook on migration (and engagement with the wider global community) can be discerned in the combination of historical experience, in the practical regulation of migrants in Japan's workforce, and in political pressures and viewpoints that manifest in Japan's national discourse. This chapter will argue that Japan's national outlook divides world affairs into discrete 'Japanese' and 'non-Japanese' categories; this produces a binary, 'us-and-them' mindset in policymaking that profoundly influences Japan's interpretations of the significance of people, ideas and events on the world stage. This chapter will argue that, due to this mindset, Japan's policymakers have failed to effectively respond to the challenges of global action. As a result, Japan's immigration policies have failed to keep pace with trends in global population movement and transnational labour migration. Overall, in this chapter I will argue that Japan remains reluctant to accept migrants because of fundamental policy structures and assumptions - arising from a binary 'us-and-them' approach to world affairs - that no longer adequately respond to the realities of transnational population movement in the early twentyfirst century.

\section{The mindset of Japan's policymakers: Japan vs. the global 'other'}

As noted in Chapter Three, conventional explanations of Japan's ambivalent relations with migrants explore and reiterate arguments of Japanese institutionalised racism and xenophobia, cultural 'uniqueness' and the ethos of a homogenous society. These explanations, seemingly consistent with the experiences of many migrants and long-term visitors to Japan, ultimately fail to provide adequate frameworks with which to interpret Japan's resistance of immigration reform. In order to more fully understand Japan's reluctance to accept migrants, a more comprehensive analytical framework for the attitudes and motivations of Japanese policymakers is required. 
Here, I argue that institutionalised racism, xenophobia and the supposedly 'unique' makeup of Japanese society contribute to a larger binary 'us-and-them' mindset on the part of Japanese policymakers. This mindset holds Japan to be fundamentally separate from the global community to a degree beyond ordinary patriotism or pride in national traditions and values. The mindset is best summarised as a broad conception of world affairs that juxtaposes Japan as a nation against foreign countries, cultures and institutions collectively. As such, Japanese policymaking de-emphasises Japan's role as a powerful player and participant in a globalised system of economic and diplomatic relations. This mindset shapes policymaking over a range of foreign and domestic issues, and is of central importance to debates over immigration reform in Japan. I will examine this mindset through discussion of three key subject areas: Japan's historical relations with other nations and the international community; Japan's track record of practical limitations and restrictions on migrant worker integration; and political factors that have shaped debate over definitions of Japanese national identity. Taken together, these three discussions help to clarify the origins, current effects and future implications of Japan's binary approach to global relations.

\section{Japan's historical relations with foreigners}

Japan has had a conflicted historical relationship with the outside world. Attitudes to relations with the global 'other' have fluctuated over time between extremes of open engagement and complete seclusion in accordance with prevailing social and political conditions of respective historical periods. Many foreign observers recognise the legacy of these historical fluctuations in Japan's present-day insularity and hesitancy to welcome people and ideas from abroad, while simultaneously embracing foreign technology and ideas and adapting these exclusively for use within Japan's own social and economic setting. This historical pattern applies equally to the integration of migrants. Gaikokujin (foreign nationals) have always occupied the fringes in Japan, allowed to work only in the occupations that Japanese society itself has shunned. Contemporary Japanese attitudes to migrants and immigration are closely connected to Japan's historical experiences. This connection is a central element of the reasons why policymakers and the public in general are reluctant to accept policy changes that could help to successfully integrate migrants into Japanese society. 
This section is intended to outline the influence of historical events on current policymaking attitudes toward migrants in Japan. By assessing the implications of Japan's interactions with foreigners in modern history, it is possible to observe precedents for an impulse in contemporary policymaking to insulate Japan against foreign intrusion. Further, specific historical events provide insight into the reasons why migration is not generally viewed in Japan as a favourable strategy to alleviate the effects of depopulation today.

Legacies of historical events are evident today in policies that clearly aim to minimise Japan's exposure to events, ideas and people from abroad, while also maintaining a strong grip over Japanese domestic economic and political affairs. A recurrent theme in Japan's foreign affairs is the effort to insulate Japan against outside influence in its various forms. This goal often comes into conflict with Japan's wider political and economic objectives, marginalising Japan within the international community and magnifying the negative consequences associated with failure to engage effectively with global systems. Inwardlyfocused policies have cut Japan off from effective global lines of communication, leaving the nation particularly vulnerable to the effects of political developments abroad. This pattern can be seen in the examples of colonial pressure on Japan during the nineteenth century, burgeoning Japanese nationalistic ideology and militarism in the early twentieth century, and the strategic manipulation of Japan in East Asian Cold War politics by western powers following the Second World War. Fluctuations in the global economic system have also impacted harshly upon Japan, as a result of occupying a single-minded niche in the global economy built upon political support for export industries above other sectors.

Many in Japan argue that the country remains as isolated and vulnerable to foreign 'interference' as ever. Pyle (1983) identifies 'siege psychology' as a motivating factor behind Japan's reluctance to engage with the global community, arguing that global economic relations have been "the most frequent source of this psychology as Japan has been besieged by western industrial nations demanding that it restrain its exports, sign orderly marketing agreements, reduce its current account surplus, open its market, and accelerate its imports" (p. 297). Along similar lines, Van Wolferen (1989) states, "it has become common for officials and prominent commentators to suggest that their country has fallen victim to widespread international ill-will, and they are apt to dismiss unfavourable analyses as 'Japan-bashing'" (p. 1). Further, former Japanese colonial territories vociferously demand that Japan accept greater responsibility for wartime atrocities and offer apologies and compensation to victims 
of Japan's wartime 'Greater East Asia Co-Prosperity Sphere'. China and South Korea's growing economic power status has emboldened those countries to forcefully demand revision of Japanese domestic policies relating to diplomacy, education and interpretation of Japan's Peace Constitution. Indefinite dependence on the United States for security resulting from Article 9 of the Peace Constitution - has only served to heighten frustrations over foreign influence, adding weight to fears of foreign threats to Japan's national interests and sovereignty.

As will be seen in the examples that follow, the influence of foreign communities and powers over Japanese affairs has contributed to a highly-insular outlook on the part of Japan's contemporary class of policymakers. Discussion of each of these will contribute to an overall understanding of why Japan maintains a restrictive immigration regime today.

For much of the Tokugawa era, foreigners were completely excluded by decree from Japanese society and territory. Japanese subjects were similarly forbidden from leaving the country or from coming into contact with foreigners - these measures, enacted in the 1630s, were referred to as sakoku ('closed country'). At its height, this policy totally proscribed interactions between Japanese subjects and foreigners, with the single exception of an isolated trading post in Nagasaki (Dejima) created as a point of contact with Chinese merchants and representatives of the Dutch East India Company. The policy reflected fears of European imperial expansion in East Asia in reaction to the influence of Portuguese and Dutch Christian missionaries, who were seen as a source of competition to the authority and power of the Tokugawa shogunate; in 1639 the shogunate decided to specifically exclude Portuguese trading ships from Japan due to concerns regarding the "insidious Christian cargo that they bore" (Kazui \& Videen, 1982, p. 292). ${ }^{5}$

The crucial historical point of change was the arrival of an American fleet of warships commanded by Commodore Matthew C. Perry in Japanese coastal waters in 1853. The threat of a forced opening to trade marked the end of national seclusion and the beginning of an era

\footnotetext{
${ }^{5}$ Sakoku also reflected a long tradition of military and cultural antagonism between Japan and other Asian countries. The reunification of Japan under the Tokugawa shogunate had itself taken place in the wake of a series of destructive military expeditions against Korea launched by Hideyoshi Toyotomi during the 1590s. Perpetual political anxiety about Japan's strategic vulnerability as an island territory dates back to the Heian era and beyond, and is noted in Japan's traditions, mythology and interpretation of ancient historical events perhaps the best-known example being the original kamikaze ('divine wind'), a semi-mythical storm that destroyed Mongol invasion fleets threatening Japan in 1281.
} 
that would bring enormous development to Japan's politics, economy and society. Faced with the possibility of military conflict with western powers over access to Japan's markets, Japan entered into the Kanagawa Treaty with the United States in March 1854. The treaty allowed for the opening of Japanese ports to American trading ships, among other concessions; this expanded further under the Treaty of Amity and Commerce in July 1858. Forced engagement of the Tokugawa shogunate with western powers and the unfavourable terms of these trade agreements contributed to political tensions with daimyo (regional lords) and the Japanese imperial court that ultimately led to the fall of the shogunate and the advent of the Meiji Restoration in 1868 (Perez, 1998, pp. 86-91). Following the restoration of imperial rule, Japan embarked on a process of open engagement with foreign ideas and technological development that eventually permitted Japan to become a preeminent industrial and military player in world affairs by the turn of the twentieth century.

Fundamental reforms of the newly-created national government of the early Meiji era, such as the Charter Oath of April 1868, demonstrated a massive shift in outlook from previous eras regarding the influence of foreigners in Japan. For the first time in the modern age, foreigners were welcomed as a source of information and technical knowledge to be utilised in securing Japan's independence from colonial powers and in pursuing the goal of rapid modernisation (Perez, 1998, p. 94). Emblematic of the era was the concept of wakon yosai ('Japanese spirit with western knowledge') - the idea that modern developments in technology, economics and politics could be imported and utilised in a way that maintained unique Japanese perspectives and cultural norms (Sawamura, 2002, p. 343). To this end, foreign experts in engineering, agriculture and industry were employed by the national government as oyatoi gaikokujin ('hired foreigners') to aid in Japan's development of modern skills and knowledge. A period of changed perspective regarding the desirability of foreign (and specifically 'western') influence in Japanese society and political affairs - the so-called kaikoku ('open country') period - also served as an important historical precedent for modern political development, as Japanese policymakers opted to embrace foreign influence as a strategic step toward bolstering Japan's power in the region. Nevertheless, distrust of foreigners remained; even the most eminent of foreign experts present in Japan at that time discovered that "while a foreigner could win the respect and sympathy of the Japanese people by exercising great deference to their culture and social needs, his welcome in the country was still limited in duration and degree" (Gooday \& Low, 1998, p. 102). Nevertheless, rapid 
technological, military and political development around the turn of the twentieth century, and growth of Japan's modern industries and military capabilities, reflected an important new epoch in Japan's engagement with world powers.

The transition from dependence on foreign technological expertise to emergence as a regional power created a surge in Japanese nationalistic sentiment, manifested in a change from a spirit of cooperation with the wider international community to one of confrontation and aggression over Japan's imperial and territorial demands as envisioned in the concept of the 'Greater East Asia Co-Prosperity Sphere'. The influence of Japan's military over domestic political affairs led to a desire among Japan's leadership for territorial expansion abroad, beginning with the annexation of Korea in 1910. This developed into confrontation with the west, culminating in Japan's attack on Pearl Harbour in 1941. The conduct of Japan's military and the attitudes and policies of colonial administrations in conquered territories inflicted such severe damage on Japan's image among its geographic neighbours that the issues of war culpability and atrocities still have a profound influence on diplomatic relations between Japan and former colonies today.

Much political resistance to foreign integration and influence in Japan relates to twentieth century militarism and territorial aggression in one respect or another; for instance, right-wing opponents of the current national history curriculum in public schools argue that contemporary interpretations of this period were forced upon Japan from abroad following the Second World War (Jeans, 2005, p. 190). The vociferous protest and diplomatic rebuke Japan continues to receive from China, South Korea and elsewhere following periodic attempts to 'tone down' war culpability as part of history lessons in schools are cited as unjustifiable foreign interference in Japan's domestic political and historical discourse (Pyle, 1983, p. 299).

The impact of total military defeat in 1945 led Japan into a postwar period of political uncertainty. Postwar occupation heightened foreign involvement in Japan's domestic affairs and foreign policy. Japan's political structure was to be profoundly influenced by developments in the Cold War abroad, particularly events taking place in China and Korea. Political pluralisation and many liberal reforms of the immediate postwar period were diluted or reversed in efforts to ensure that Japan would not fall under Communist influence. In this unstable political climate, the business conglomerates that were a characteristic feature of 
Japan's wartime economy (and that had been broken up following Japan's defeat) were allowed to regroup, and centre-right political parties coalesced into the extremely powerful LDP, which would come to dominate electoral politics in Japan over the second half of the twentieth century. Prime Minister Shigeru Yoshida's government entered into a Security Treaty between the United States and Japan that took effect in April 1952, guaranteeing American strategic military support in exchange for allowing American military personnel to be stationed on Japanese soil.

The Yoshida Doctrine prioritised economic recovery and growth over sovereign independence in foreign relations; many conservative observers came to interpret this as another example of foreign interference in Japan's domestic affairs, drawing parallels between the Mutual Security Treaty and the 'unequal' agreements forced on Japan by the United States almost a century earlier at the time of the Kanagawa Treaty (Perez, 1998, pp. 161-162). A lack of leverage for Japan's government in negotiations with the United States over mutual security led to the resignation of Prime Minister Yukio Hatoyama in June 2010, following failure to secure the relocation of Marine Corps Air Station Futenma in Okinawa (Hongo, 2010). ${ }^{6}$ The indefinite presence of American military bases on Japanese territory presents an image to the public of enduring diplomatic weakness and subservience to the United States on matters of global security policy, along with broader dependency on the United States to defend Japan from challenges and threats in Japan's geographic region and former colonies.

Dependence on international allies for security contrasted with Japan's status as a world economic leader during the latter half of the twentieth century. In tying Japan's military and defence interests to cooperation with the United States, the Yoshida Doctrine shifted the national focus towards economic recovery and growth. As a result, Japan enjoyed a period of sustained economic growth from the 1950s to the 1980s, re-establishing Japan's credibility as a world political and economic player. Government-subsidised investments in key industries and manufacturing sectors (such as steel, chemicals, electronics, car-building, ship-building and other heavy manufacturing ventures) developed Japan into a large-scale

\footnotetext{
${ }^{6}$ The U.S. military presence in Japan remains a controversial subject, attracting an unusual degree of protest and condemnation from the Japanese public. This strength of feeling primarily relates to the conduct of American military personnel within local communities, symbolised in public opinion by the abduction and rape of a schoolgirl by American servicemen in Okinawa in 1995, an incident that provoked widespread public outrage and resentment throughout Japan (Shimizu, 2008).
} 
export producer, and were tied to policies discouraging domestic consumer spending and promoting high savings and investment rates (Prestowitz, 2010, p. 34). As western companies increasingly sought inspiration from Japanese corporate models and management techniques, Japan was again able to exert international influence as a world leader and economic power. ${ }^{7}$

This period of economic growth, development and prosperity came to an abrupt halt at the end of 1989 with the sudden collapse of Tokyo real estate prices and the consequent deflation of Japan's ‘bubble economy'. Stagnant economic growth throughout the 1990s (the so-called 'lost decade') and the fall of Japanese banks from world-leading status to a position of comparative obscurity in global finance caused world attention to shift away from Japan in favour of the rising Asian economic powers such as Malaysia, Taiwan, Singapore, China and South Korea. As a result of the 2008 recession and global economic downturn, an exaggerated dependence on exports has caused Japan's economy to further contract. The inability of domestic consumption in Japan to offset declines in export sales suggests that Japan's prospects for economic recovery will ultimately be determined to a great extent by the ebb and flow of foreign demand for Japan's exported goods, subject to intensifying competition with China and other major exporters in the region (Tabuchi, 2009).

Japan's present-day resistance to immigration reform must be understood in the context of these historical events, as they represent the background and origins of contemporary attitudes to foreigners. Essentially, early missionary activities in Japan from the mid-1500s established an enduring distrust of the motivations of foreigners with regard to Japan's national interests. This distrust came to characterise even the comparatively open Meiji era, and was intensified during periods of war with foreign powers. Strategic manipulation of Japan during the Cold War only served to cement suspicions that Japan would remain dependent on stronger allies and vulnerable to the consequences of foreign political goals and priorities. Distrust of foreign influence is perceptible today in policies that aim to consolidate the personal details of migrants and that impose severe restrictions on Japan's foreign residents (to be discussed in the section that follows). Similarly, foreign

\footnotetext{
${ }^{7}$ It was during this period that Japan's government first experimented with accepting labour migrants of Japanese ancestry from Latin America, addressing a shortage of unskilled labour that had appeared as a result of improved living standards and rising wages in the Japanese labour market. These migrants were required to fill positions described as ' $3 \mathrm{~K}$ ', a term derived from the Japanese kitsui ('difficult'), kitanai ('dirty') and kiken ('dangerous'), which gradually came to be shunned by a growing middle-class of educated Japanese workers in favour of white-collar careers.
} 
economic interests are perceived in Japanese business circles to have challenged and undermined Japan's postwar economic successes (Wood, 1992, pp. 28-29). For these reasons, calls from abroad for Japan to enact immigration reforms have met with a negative reception on the part of Japan's government and bureaucracy.

However, historical events represent only part of a larger understanding of Japan's current immigration policy outlook. The next section will discuss current immigration and labour policy implementation in Japan, addressing the ways in which the instinct to insulate Japan from foreign influence (as described above) manifests in contemporary migrant hiring and employment practices.

\section{Migrants and Japan's labour market: Barriers to participation}

Though Japanese policymakers apparently prefer not to reform immigration policy for historical reasons, abject shortages of labour in crucial sectors of Japan's economy have created considerable pressure in favour of allowing migrant workers to make labour contributions in many important industries. Though Japanese employers are often eager to hire migrant workers to make up for local labour shortages, complicated bureaucratic obstacles stand in the way of effectively employing migrants in Japan's businesses and social services. These obstacles severely restrict employment opportunities for migrants and undermine the basic viability of migrant employment in key sectors of the economy, even in cases where those positions cannot realistically be filled by Japanese workers. Though it can be argued that migrant employment initiatives have potential to improve economic outcomes for Japanese society and industry, and represent negligible competition to domestic workers, Japan's immigration and employment laws have conspired to systematically undermine legitimate hiring of workers abroad.

Foreign employment in the healthcare sector in Japan provides an illustrative example of difficulties in securing and employing migrant workers, even those with highly-specialised skills. As Japan has aged rapidly in demographic terms, a huge employment shortfall has developed in caregiving services for the elderly. The number of nurses and home helpers required to meet the needs of Japan's aged population is projected to grow to 470,000 by the year 2025, a 40 percent increase on 2005 employment levels in that sector (Coulmas, 2007, p. 
120). Some of this shortfall is expected to be made up through semi-formal social policy changes, by calling on retired healthcare professionals and community volunteers to contribute to elderly care to a greater extent in the future (BBC News, 2009). Healthcare has been one of the first highly-skilled professional sectors in Japan to benefit from a limited relaxation of labour laws, allowing trained migrants to work in Japan as a component of bilateral trade liberalisation. Fully-qualified nursing staff and certified caregivers from the Philippines and other Southeast Asian countries are permitted to work in Japan for periods of three or four years, with the same rights and protections enjoyed by Japanese staff in similar positions. However, these workers are required by law to pass extremely demanding Japanese language proficiency tests involving knowledge of highly-specialised medical terms in order to extend their work visas beyond the initial three or four year employment period, a goal that as few as 2 percent of candidates successfully achieve (BBC News, 2010b). Regulations stipulating these kinds of conditions restrict migrant employment in two ways: they drastically reduce candidate numbers to the few who can successfully meet the exceedingly demanding language and professional requirements demanded under the law, and discourage Japanese organisations from hiring migrant workers because of the likelihood that they will fail to meet these requirements.

The cases of skilled Filipino workers filling critically understaffed positions in Japan compare with those of Nikkeijin, or Latin American workers of Japanese descent that began to return-emigrate to Japan in large numbers during the 1990s as part of a government strategy to fill unskilled positions in the then-booming manufacturing and heavy-industry sectors, particularly around industrial centres in Aichi, Shizuoka, Gunma and Kanagawa prefectures (Shipper, 2008, p. 39). The decision to allow Nikkeijin to live and work in Japan was closely tied to Japanese lineage, based on assumptions that migrants of Japanese ethnic descent would be better able to adapt to Japan's society and culture. It was intended that this would negate the social and economic costs of migrant integration, even though those migrants had mostly never lived in Japan previously, spoke little or no Japanese, and were accustomed to the cultural values and practices of their home countries. As Japan's unemployment rate began to climb in an era of economic downturn, official perceptions of these previously-favoured Nikkei labourers changed markedly in the context of debates over foreign workers and Japan's unemployment problems. 
Observers such as Shipper (2008) and Yamanaka (2008) link Nikkei immigration policies to deep-seated exclusionary attitudes on the part of Japan's Ministry of Health, Labour and Welfare, arguing that these attitudes have produced stratified or tiered immigration and labour policies depending upon the specific ethnic and cultural backgrounds of the immigrant communities involved. As Shipper puts it, "this racialised hierarchy - which produces differentiated jobs, wages, rights, and privileges for different groups of foreigners is a political construction of the Japanese government, rooted in a cultural view that certain races and nationalities are uniquely qualified for certain kinds of labour" (p. 25). Though Nikkeijin were at first assumed to enjoy advantages by virtue of ethnic fraternity with the wider community in Japan, evidence suggests that Nikkeijin suffer significant social discrimination, meeting with "a cold reception by the Japanese who regarded and treated them as inferior to true Japanese" (Yamanaka, 2008, p. 189). Nikkeijin have also endured exploitation in the workplace as a result of the subcontract-based models of businesses that typically employ Nikkeijin, which facilitate little or no access to public or private health, welfare, employment or accident-related insurance benefits (Shipper, 2008, pp. 40-41).

Tolerance of Nikkeijin deteriorated further as unemployment levels increased steadily following Japan's 1989 economic collapse. Nikkeijin are now subjected to government pressure to encourage repatriation to South America as part of efforts to improve the appearance of domestic unemployment statistics. Following the global economic recession of 2008 and downturns in Japan's export sales and production, Nikkeijin were invited to take a repatriation allowance of 300,000 yen (with additional payments for each family member) to leave Japan permanently under an emergency measure introduced by the Ministry of Health, Labour and Welfare in April 2009. Approximately 17,000 people had accepted the offer of paid repatriation by the end of that year (OECD, 2010). Such a massive policy reversal (from promoting return migration to rejecting return migrants) serves to demonstrate the tenuous degree of tolerance of migrant workers in Japan's labour market today.

Repatriation of Nikkei return migrants raises the question of whether migrant workers in Japan actually threaten to deprive local workers of their livelihoods, particularly in light of the 'dirty, difficult and dangerous' nature of the work migrants are generally hired to undertake. An example of the image of migrant labour as a threat to mainstream workers was provided in 2004 by a controversial website created by the Ministry of Justice Immigration Bureau. This provided an outlet for Japanese citizens to anonymously inform on foreign 
residents suspected to be overstaying or working illegally in Japan. According to media reports at that time, suggestions on this website (as justifications for submitting reports on foreign residents) included, "Was fired due to violator", and "Couldn't get work due to violator" (Arudou, 2004). As seen in this instance, unemployment problems in Japan have already been attributed to migrants by government and bureaucratic sources.

In considering whether empirical evidence supports claims that migrant workers embody a threat to employment for local workers, Rudolf Winter-Ebmer and Josef Zweimuller (1999) argue that strategies intending to address unemployment by removing migrant workers from the labour market typically overlook important economic and social realities of labour migration in host countries. These include recognition that immigrant workers often cannot perfectly substitute for local labour in most industries and professions, that wages for migrants and costs of their employment do not always undercut those of local workers, and that immigrants cannot necessarily replace local workers on a direct one-to-one basis without creating complicated follow-on effects for economic development. Regardless of these arguments, potential employers of migrants in Japan must contend with negative public perceptions of migrant responsibility for high unemployment levels. This view is endorsed by Japan's government, as can be seen by the targeted removal of migrant workers in response to public disaffection over unemployment, leading to harsh official crackdowns on migrants in the mid-2000s (Clark, 2009). This situation endures in Japan today, even as many Japanese businesses find themselves in desperate need of workers.

Partly as a result of the practical difficulties associated with legitimate migrant employment in Japan, some industries hire migrants in an illegitimate capacity, often as undocumented labourers or as 'entertainers' (a common euphemism to describe roles in the hospitality, nightclub or sex industries). These businesses provide livelihoods for many thousands of undocumented migrant workers in Japan. While these workers generally enter Japan legally with short-term visas, they are often compelled by poor wages and personal circumstances to remain in Japan illegally after the expiry of their visas. This scenario is reported in the cases of women from Asian countries entering Japan under 'entertainer'category visas whose illegal status is exploited by predatory employers, who compel them to work as bar hostesses and prostitutes (The Japan Times, 2005). The difficulty of obtaining valid work visas in Japan has facilitated a proliferation of human trafficking networks, creating opportunities for organised crime syndicates to become powerful players in migrant 
employment. Labour shortages have also created parallel demand for undocumented manual labourers to take on the most arduous of ' $3 \mathrm{~K}$ ' jobs in Japan; by the late 1990s, approximately 300,000 undocumented migrants were estimated to be working in Japan, in addition to legally-documented migrant workers employed in roles outside the stipulated conditions of their visas (Douglass \& Roberts, 2003, p. 7).

The visibility of migrant workers in Japan, and misleading associations of foreign workers with unemployment and economic problems, are used by Japan's policymakers to justify political inertia and bureaucratic resistance to immigration reform. Efforts to crack down on migrant employment by agencies such as the Ministry of Justice Immigration Bureau enjoy official and popular support; the discretionary powers of Japan's Justice Minister to issue special amnesty permits to undocumented migrants in Japan have been strenuously opposed by conservative groups (Matsutani, 2009). This climate of opposition further exacerbates the difficulties of legitimate Japanese employers that could benefit from the labour of migrant workers under more favourable conditions. As Clark (2009) states, Japan at present "is busy expelling just the kind of people it says it needs".

The examples noted in this section demonstrate how practical obstacles to legitimate migrant employment in Japan are often closely tied to cultural considerations and politics of national identity. Of course, this is also the case in many other host countries. However, I contend that interactions between historical, practical and cultural factors characterise Japan's responses to demographic change in a distinctive way. In the following section, political and cultural arguments against allowing a greater migrant worker presence within Japanese society reveal the central importance of monoethnic and monocultural ideology to Japan's policymaking structure. As we have already seen, similar arguments inform many conventional interpretations of reasons for Japan's unwillingness to implement immigration reform. In contrast, the discussion that follows will reveal how social structure and political expediency produce a binary, 'us-and-them' policy perspective that ultimately holds back reform of Japan's immigration regulations. 


\section{Cultural and political constraints}

Japanese perspectives on immigration reform must be understood with regard to political pressures and constructions of a unified national identity that became dominant during the second half of the twentieth century. As we have already seen, the assumption of Japan being a monoethnic and monocultural society has been central to Japan's social policy debates, both within and outside the country. Though perceptions of Japan as the seat of a unique language, culture, heritage and ethnicity have resonated in domestic politics since at least as far back as the Tokugawa era, the concept of Japan as a fully homogenous and unified society came to be firmly established after the Second World War. Enduring belief in this concept on the part of officials and the public at large leaves non-Japanese migrants isolated and vulnerable to political harassment. Foreign communities have been targeted and blamed by government agencies and conservative politicians not only for Japan's present economic weaknesses and unemployment, but also for crime and other social problems.

Japan's demographic crisis challenges policymakers to ease economic and social symptoms of depopulation while also striving to sustain idealised concepts of a 'pure' homogenous society. Evidence suggests that government agencies engage in open cultural discrimination in order to justify policies that seek to uphold the ideal of a homogenous society against calls for liberalised immigration reform. In this section, examples of these policies and practices will be discussed in order to clarify prevailing attitudes toward migrants among Japan's bureaucratic and political elites. The fundamental reasons for these attitudes are complex, as rapid changes in Japan's influence and prestige in the world have joined with pressing problems in Japan's governing institutions at home to discourage more extensive efforts toward intercultural engagement.

The object of establishing an ideology of cultural and linguistic uniformity across the country, and of promoting the concept of a monoethnic and homogenous Japanese society, evolved over time from a reflection of nineteenth-century imperial and colonial beliefs in natural racial and cultural hierarchies toward a desire for social and political stability as a platform for continued economic growth. Lie (2001) refers to this development as "the rise of a new nationalism born of newfound prosperity" (p. 132). Social stability and predictability developed into a central policy priority for the LDP during a fifty-year period of electoral ascendancy, enjoying widespread and prolonged popular approval. As Lie states, "Many 
supported the conservative Liberal Democratic Party not so much as a principled ideological position but rather to preserve the stability of everyday life" (p. 49). The outcome of this has been that social homogeneity has now become an established framework of public debate over the role of migrants in Japanese society. This framework shapes contemporary debate with little consideration given as to whether monoethnic and monocultural assumptions remain valid, or whether they provide suitable foundations for sustainable social policy. Advocates of migrant rights and migrant employment in Japan have been obliged to engage with the debate under conditions in which, as Lie states, the terms of "explicit discussion of new foreign workers almost always brought the presumption of Japanese monoethnicity to the forefront" (p. 49).

Japanese government policy throughout the twentieth century has reflected a discourse of ethnic and cultural homogeneity. This view has profoundly affected not only the lives of foreign residents and communities in Japan, but also those of indigenous groups whose languages, cultural practices and ethnic backgrounds serve to undermine the validity of monocultural ideology. ${ }^{8}$ This section will discuss and explain the effects of these attitudes and policies, arguing that migrant communities are key examples of diversity in contemporary Japanese society.

Beginning in the early 1870s, Japan's central government implemented policies to assimilate indigenous ethnic and cultural minorities into the dominant culture under the guise of educating and civilising the extremities of Japanese territory. These policies laid foundations for the denials of diversity at the heart of Japan's monoethnic and monocultural ideology today. A range of laws were passed (such as the Hokkaido Former Natives Protection Act of March 1899) that prohibited the exercise of indigenous customs such as tattooing, ear piercing and traditional hunting, and included regulations that discouraged the use of indigenous language and that forced indigenous communities to relocate away from valuable agricultural land. In the case of the Ainu, Japan's central government until very recently refused to acknowledge or accept responsibility for these policies and events. Despite Japan's vote in favour of the United Nations (UN) Declaration on the Rights of

\footnotetext{
${ }^{8}$ Examples of prominent indigenous ethnic and cultural groups in Japan include the Ainu of Hokkaido, native inhabitants of Okinawa, and also to some extent burakumin, or descendants of an historical social underclass long associated with occupations such as undertaking, butchery, leatherworking and other trades considered to be impure by conventional Japanese social standards.
} 
Indigenous Peoples in September 2007, the government still refused to officially recognise the status of Ainu as an indigenous minority group until as recently as June 2008 (Ito, 2008). A similar series of policies affected native Okinawans from the time of Okinawa's annexation in 1879. Centralised education and regulations aimed to assimilate Okinawan society into mainstream Japan and sought to suppress local languages and customs in favour of "the spirit of the Japanese nation" (Allen, 2009, p. 192). These colonial policies set an important precedent for the development of modern monocultural ideology.

Policies that came to assume cultural and ethnic homogeneity evolved further in the large-scale urban shift and decline of regional loyalties and diversity that occurred as part of industrial recovery and expansion from the 1950s onward. These policies brought about the cultural integration of mainstream society around Japan's industrial economy during the 1960s (Lie, 2001, p. 126). Examples of regulations of the period that aimed to sustain ideals of Japanese social homogeneity can be seen in residency laws that specifically related to Japan's 'special permanent residents', in particular Zainichi communities (a term describing long-term Korean residents of Japan). Korean migrants that entered Japan during the period of colonial rule were deprived of the right to political representation by an amendment to Japan's Election Law in December 1945, and were declared to be foreign nationals (thereby denying many human rights protections) in the context of Article 13 of the Peace Constitution (Shipper, 2008, pp. 32-33). As a consequence of these measures, even those Zainichi who had been born in Japan were required to submit to fingerprinting and to carry alien registration documents. The only way for Zainichi to avoid these discriminatory measures was to become a naturalised Japanese citizen, a process that required the renunciation of one's Korean name in favour of a Japanese name (Shipper, 2008, p. 34). Those who chose to retain their Korean cultural identity and name were regarded in Japanese law as foreign residents until 1965, when the 'special permanent resident' visa category was introduced, but continued to be subject to fingerprinting as part of alien registration until as recently as $1993 .{ }^{9}$ Zainichi currently also remain prohibited from voting in national elections or seeking employment in most of Japan's national civil services (Shipper, 2008, pp. 34-35). These

\footnotetext{
${ }^{9}$ Increased border security resulting from international terrorism concerns have been invoked as justification for a return to fingerprinting of migrant communities in Japan, a practice that had been finally abolished in 1999 after a campaign of sustained public pressure from non-governmental immigrant solidarity groups (Chung, 2010, p. 2).
} 
policies provide indications of the philosophical outlook in policymaking circles toward the rights and social roles of non-Japanese residents, and demonstrate some of the methods used to exclude non-Japanese residents based on ethnic and cultural background. As Chung (2010) observes, "The official stance toward immigrants suggests that non-Japanese do not have the capacity to become Japanese and, therefore, should be excluded" (p. 3).

Counterbalances to Japan's monocultural orthodoxy are provided primarily by nongovernmental organisations concerned with promoting intercultural understanding and acknowledgement of rights for migrants and foreign residents. These organisations organise collective action around important issues affecting foreign residents in Japan (such as the Zainichi fingerprinting controversy), collect statistics relating to foreigners and migration, inform migrants of their legal rights and obligations, submit proposals to government agencies regarding public policy affecting migrant workers and foreign residents, and publicise some of the difficulties faced by foreigners in mainstream public discourse (Shipper, 2008, pp. 166-171). These initiatives have helped to reshape expectations in Japan as to the responsibility of government at all levels to provide social services for non-Japanese residents (pp. 128-129). Advocacy organisations for migrants have typically operated under the auspices of wider social activist networks in Japan, comprising faith-based groups, worker unions and women's support groups, as well as legal and medical not-for-profit community organisations (pp. 89-90). The existence of these organisations and their modest successes in creating a more inclusive atmosphere for migrants in the public arena indicate that acceptance of homogenous social ideology in Japan is far from universal. Nevertheless, their potential to bring about proactive long-term change in Japan's social attitudes in the face of conventional monoethnic social messages is heavily restricted by established policies based around homogenous ideals.

Given the importance of monoethnic and monocultural ideology to Japan's political culture, the prospect of allowing large numbers of migrant labourers into Japan threatens to bring fundamental change to established interpretations of Japanese national identity. In the past, migrant communities have typically been isolated and dispersed, with few outlets for political representation and little real power to agitate for greater recognition or rights. Much political opposition to immigration reform stems from fear of the potential political power of migrant communities unified around common interests. Such a situation occurred in the early 1990s, when significant numbers of Iranian immigrant labourers began to congregate socially 
in Yoyogi Park in central Tokyo. By creating a large and highly-visible mass presence in a prominent public place, displaying distinctively foreign cultural traits and practices (such as makeshift street vendor markets), the gatherings stirred considerable discomfort among officials and members of the public, and were eventually blocked in 1993 on the pretext of carrying out renovations and beautification (Machimura, 2003). Essentially, visible migrant communities from non-East Asian ethnic and cultural backgrounds are seen to embody a threat to policy structures based on homogenous social ideals.

As a central premise, Japan's discourse of social homogeneity assumes not only that Japan is monocultural today, but has always been so throughout history, regardless of the fragmented state of Japanese society and culture prior to the Meiji Restoration; as Lie (2001) puts it, "The recent vintage of monoethnic ideology does not prevent the imagined present from transforming the misty past in its image" (p. 141). Gatherings of migrant groups create an impression of unrestrained social change being imposed upon society from beyond Japan's shores, and raise the prospect of immigration reforms leading to public displays of migrant solidarity, raising fears of the potential for migrants to engage in unified mass political action. This situation perhaps reflects an uncomfortable discord between contemporary national identity discourses based on social homogeneity, and the obvious multicultural realities to be observed in Japan's urban centres. For these reasons, current immigration policy is directed at ensuring that migrant communities blend into society in ways that are neither clearly visible nor unified to the extent that they could eventually develop into forces for change within Japan's political system. According to Machimura (2003), Japan's immigration policy has been constructed in such a way that "ordinary Japanese citizens have little exposure to [foreigners] and thus little opportunity to develop a positive image of them. The widespread stereotype that migrant workers might be illegal has enhanced negative attitudes" (p. 186). As a result, growth of foreign communities "has often brought about a conservative or defensive attitude among local Japanese residents" (p. 187).

The presence of migrants in Japanese society on a significant scale also threatens a model of social and ethnic uniformity considered indispensible by many in government and bureaucracy to Japan's postwar economic successes. As such, the beliefs that underlie this ideology continue to profoundly affect policymaking today. The lack of precedent for a mass influx of foreign settlers into Japan is an important component in explanations for why migrant communities face such antipathy to their presence. Conflict between Japan's 
economic need for access to migrant labour and political and social desires to maintain at least the facade of monoethnicity introduces a form of cognitive dissonance to Japanese politics; as demographic problems continue to develop, they may force substantial (and unwelcome) re-examinations of Japan's cultural identity. Put another way, the demographic and economic compulsion to employ large numbers of migrants in Japan has potential power to change the very social frameworks and belief systems to which Japan's postwar economic successes are attributed by the government and bureaucracy.

The resonance in political discourse of images of migrants causing 'disruption' to social and economic 'harmony' encourages politicians and conservative commentators to court popular support by promoting negative representations and stereotypes of foreigners. As has already been mentioned, conservative Japanese politicians and bureaucrats regularly conflate migrant communities with national crime rate increases, economic problems and domestic unemployment. Politicised attacks on immigration reform and migrant workers serve the short-term interests of conservative politicians and bureaucrats "as part of their strategies to garner political support and/or institutional expansion within the government" (Shipper, 2008, pp. 156-157). Negative depictions of migrants also serve to distract attention from instances of weakness in government, as confidence in politicians declined precipitously in the wake of corruption scandals involving prominent members of both major political parties in Japan - most recently that surrounding former DPJ President and Secretary General Ichiro Ozawa concerning charges of financial impropriety (BBC News, 2010c).

Hardened factionalisation of Japanese politics has also contributed to public disaffection, with a series of governments rendered ineffectual with regard to honouring election campaign promises and popular reforms. Watanabe (1997) argues that Japan's continuous economic growth from the 1950s to the 1980s imbued Japan's bureaucracy with such an immense degree of power and influence over policy that the elected branches of government today are severely restricted in their ability to exert full and independent authority over economic and social policymaking. Van Wolferen (1989) claims that Japan's present political structure renders elected officials "incapable of delivering on political promises they may make concerning commercial or other matters requiring important adjustments by one of the [other] components of the [political] system" (p. 6). This situation has produced a string of prominent policy failures and a series of prime ministerial resignations (four since the resignation of Prime Minister Junichiro Koizumi in September 2006). In this context, 
immigration reform occupies a low priority for many in government (Harlan, 2010). Consequently, officials have responded in part to problems of economic underperformance and domestic unemployment with hard-line policy stances against migrants and crackdowns on undocumented migrant workers (Masters, 2009).

Opposition to immigration reform also mobilises more extreme uyoku dantai groups in their efforts to gain influence at the fringes of the political spectrum. As already discussed, the immigration debate is a focal point for the hard-line political stances of nationalist groups in Japan. Support for more restrictive immigration laws allows Japan's conservatives to market themselves as resolute defenders of Japan's national interests from foreign interference (Matsutani, 2009).

Overall, anti-migrant sentiments in public policy and electoral politics can be regarded as a measure of uncertainty in the stability of Japan's current political and ideological structure. Confronted by the realities of demographic change and depopulation, and hemmed in by conservative bureaucratic pressures and public disapproval, government is limited in its capacity (and willingness) to take action on immigration issues in a decisive and effective way. That is to say, political disincentives to revitalise Japan's immigration regime are responsible for the apparent lack of urgency seen in official responses to demographic decline and depopulation.

The three preceding sections have related the background of government inaction in response to the demographic crisis: Japan's policymakers retain a deeply-held historical distrust of foreign communities in Japan, actively implement policies that hinder migrant participation in society and the economy, and face a range of very significant political disincentives that sap enthusiasm for immigration policy reform. But more importantly, these sections reveal the blueprint for a more profound resistance to policy reform. This is based on a conceptualisation of world affairs that severely limits Japan's options for successful engagement with modern developments and trends in globalisation that could provide new and effective solutions to Japan's demographic problems. The next two sections will describe the nature of Japan's binary 'us-and-them' mindset, discuss the ways in which this mindset restricts Japan's engagement with new models of transnational labour migration, and explain how Japan's current restricted levels of global engagement are the key to understanding why Japan persists with refusal to accept migrants today. 


\section{Japan's national concept of identity and relations with the global community}

The three broad discussions above (of historical, practical and political factors) are of central importance to understanding Japan's demographic dilemma, as they coalesce within a larger discourse of Japanese national identity and contemporary political affairs. The interaction of these three discussions helps to define the limits of a binary, 'us-and-them' mindset that regards Japan (together with national political and economic interests) to be in opposition to foreign countries and cultures collectively. Attitudes to migrants in Japan originate from this mindset, as policies restricting the participation of migrants in Japanese society derive from the same set of 'us-and-them' assumptions. This section will draw the central aspects of the preceding sections together in order to further clarify the implications of this binary view of world affairs. The final section of this chapter will discuss Japan's binary 'us-and-them' mindset in the context of modern transnational labour migration and globalisation, and will elaborate my argument that this mindset has produced a set of immigration policies that fail to keep pace with developments in global population movement and community formation.

The historical experience of Japan as an island nation has framed Japan's current view of globalised politics. Constant concern over comparative levels of military power and economic strength in competition with Japan's neighbours dating back into distant history and continuing today in the form of territorial disputes with Russia, North and South Korea and China - has acted as the catalyst for cementing strategic visions for Japan as a kind of territorial and cultural 'island fortress' (termed shimaguni konjo in Japanese, literally 'an island country mentality'). Combined with religious and spiritual traditions linking Japanese language, culture and ethnicity exclusively to the physical landmass of Japan (Hardacre, 1989, p. 5), historical events form the foundation of modern conceptions of Japan as 'unique' and 'isolated', supposedly having neither ethnic or cultural communality with other nations, nor the strategic and economic unity of purpose felt by countries participating in a global 'community of nations'. Van Wolferen (1989) argues that Japan's policymakers appear in many cases to have developed economic and foreign policy around a stance of neither having, nor wishing to acquire, a participatory stake in globalised world affairs. He claims that "Japan needs the world for its exports, to keep its economy running; but many in Japanese official positions appear to prefer their traditional isolation, wishing that the world with all its political complexities would leave their country alone" (p. 6). Similarly, Reischauer (1988) 
characterises Japan's policymakers as "simultaneously world leaders and world loners" (p. $395)$.

Seemingly intractable practical problems that actively discourage employment of migrants in Japan are typically explained away with reference to the 'unsuitability' of migrant workers in the context of Japan's workplace expectations, national work ethic and cultural values. Closer examination shows that many of the problems facing migrant workers (and potential Japanese employers) are actually deliberate policy constructs based on conservative bureaucratic attitudes and protectionist ideas. The harshest restrictions on migrant workers (such as unrealistic demands for applied language proficiency as a condition for visa renewal that exceed even the standards that are expected of Japanese nationals in the same positions) dictate that migrants find themselves massively disadvantaged in the labour market; these regulations raise the incidental costs of hiring migrant workers to unfeasible levels for most potential employers. In the social sphere, continued demands for foreigners to carry alien registration documents coupled with harassment at the hands of police and other officials negatively affect quality of life for foreigners in Japan. These examples further reinforce bureaucratic and popular belief in an idea that foreign residents are not qualified to contribute to Japan's political or social discourses, or to participate in future development of Japan's culture and identity. Faced with overwhelming disadvantages in society and the workplace, migrants are essentially rejected as social and cultural contributors due to collective inability to overcome obstacles placed before them by Japan's immigration and labour regulations. In this way, discrimination against migrants creates justification for its own continued existence in a self-perpetuating cycle, and the ideology of social homogeneity thus becomes a self-fulfilling prophecy.

As I have argued above, the reasons for this outlook must be understood in relation to historical precedent. For example, short-term hiring and periodic expulsion of foreign engineers and modernisation experts during the Meiji era became implicitly associated with economic growth, development and prosperity. Similarly, political expediency plays an important role in Japan's restrictive immigration regime; examples are seen in the MOJ's use of visa violation statistics as a rationalisation for crime rates, and as justification for greater consolidation of personal information of foreign residents. These policies and regulations reveal an 'us-and-them' dichotomy in policymaking between that which is construed to be natural, congruous and 'Japanese' in character, and that which is foreign, out of place and of 
strict utility value to Japan for the purpose of gaining access to 'outsider' knowledge and information. As Reischauer (1988) summarises, "the line between uchi and soto - between 'inside' and 'outside' - [is] clear. A person [is] by race, language, culture and nation either fully Japanese or not a Japanese at all” (p. 396).

The politics of immigration and citizenship in Japan create a policy structure that is a function of historical lore and traditional fears of 'the other' tied to self-imposed political and cultural isolation. By restricting and marginalising foreign communities in Japan, the government has also discouraged Japan's population collectively from participating actively in the global community, thereby also restricting development of a popular sense of equality in social, cultural and political engagement with other countries. Policies based on the 'uniqueness' and 'homogeneity' of Japanese society have legitimised public impressions of an unbridgeable gap between Japan and the 'outside' world, resulting in a kind of cultural insulation that contributes hugely to mainstream acceptance of the 'homogenous society' ideology itself. Further, these policies establish receptive grounds for nationalistic arguments opposing a modern Japanese identity that embraces foreign people, ideas and influences. Kerr (2001) claims that "few nations have erected such high barriers against foreign people and ideas" (p. 335); it can be seen that these barriers also apply just as effectively to mainstream Japan's own capacity and desire to engage with the outside world. Isolation and limited intercultural communication are keystones of Japan's monoethnic and monocultural ideology and of a conservative bureaucratic 'us-and-them' vision of Japan's role in the global system. As Kerr concludes, "One cannot underestimate the shock that true globalisation would bring to a social system and economy like Japan's, which depends so much on being cut off from the world" (p. 368).

A brief look at popular discourse surrounding 'Japanese uniqueness' helps to clarify the extent of isolationist thought that sustains this binary 'us-and-them' mindset. Literary material on the subject is so common that it is recognised as a distinct field of pseudoscientific academic and cultural enquiry known as Nihonjinron (literally 'discourse of the Japanese people'). Nihonjinron ostensibly aims to examine the ways in which Japan differs in a philosophical and anthropological sense from other nations. According to Dale (1986), Nihonjinron has a notable impact on the work of many scholars of Japanese culture, linguistics and social issues. He criticises the basic philosophies of Nihonjinron, characterising the field as "displaying a conceptual and procedural hostility to any mode of 
analysis which might be seen to derive from external, non-Japanese sources" (p. i). Nihonjinron is noteworthy for the way that it emphasises profound differences between Japan and the rest of the world as a generalised whole, implying the impossibility of those born outside strict Japanese ethnic and cultural bounds to fully appreciate and understand the nuances of Japanese culture, language and customs.

This attitude extends to Japanese nationals who are exposed to foreign cultures and languages by way of overseas travel or work experience. An illustrative example can be seen in the discrimination and suspicion faced by returnee Japanese children (known in Japanese as kikokushijo) who have gained experience of the world outside Japan through long-term study exchanges or parental work commitments. From the early 1970s, growth in numbers of these internationalised young people instigated the development of special education and social reintegration programmes arising from concerns that children may have "forgotten many of their Japanese language skills [...] and have become imbued with non-Japanese ways of behaving, most notably with western ideas of individualism" (Goodman, 2003, p. 178). Since the emergence of kikokushijo as a social phenomenon forty years ago, young returnees have encountered shifts in public and official attitudes and opinion, varying from sympathy regarding the educational disadvantages that overseas travel supposedly entailed, to impatience toward 'non-Japanese' attitudes absorbed while abroad, to resentment for high school, college and university quotas allowing kikokushijo to circumvent the standard national entry requirements for access to higher education (pp. 178-184). The emphasis of special programmes for the benefit of kikokushijo was "that children should be helped to become fully 'Japanese' again” (p. 181). These examples show how 'uniqueness' and monocultural ideology are reflections of a very distinctive political view of Japan at odds as a nation with an overwhelming, broadly-based definition of 'the other' that exists beyond Japan's shores. According to this view, Japanese identity is defined not in contrast with any other particular culture or country (though specific international rivalries do inform Japanese policymaking and popular thought), but with the existence of a global system outside Japan more generally.

Recognition of Japan's binary approach to global affairs and intercultural relations is an essential step toward understanding why Japan continues to resist immigration reform. This binary approach powerfully influences the direction of Japan's immigration debate in favour of the status-quo. An influx of migrants in the numbers necessary to offset demographic 
change would strike at the heart of many conventional social beliefs and messages surrounding Japanese heritage and history, compromising the foundational assumptions of Japan's national identity discourses upon which policymaking elites depend for authority and legitimacy. Further, it is very important to view Japanese attitudes to immigration within the context of globalised population movement and labour migration; though policymakers and conservative commentators in Japan may prefer not to engage with modern global migration frameworks, we will see that continued adherence to the isolationism of an earlier era locates Japanese policymakers firmly within a larger debate over effective utilisation of migrant labour in the twenty-first century. By turning attention now to international and globalised experiences of labour migration, I will connect Japan's policies with well-established discourses of labour migration and economic development within the globalising international system. Taken together, these components will be developed into the core set of explanations for why Japan persists with refusal to implement immigration reforms, which are based on Japan's present inability to effectively engage with globalised systems and communities.

\section{Labour migration and globalisation}

Japan's reluctance to consider immigration reform represents just one aspect of larger global debates over the development of modern transnational labour migration patterns. As such, an overview of modern migration in terms of trends in policy and academic analysis provides context for interpretation of Japan's immigration conundrum. Generally speaking, scholars of transnational labour migration have identified broad shifts in approaches to understanding the effects and implications of transnational labour migration policy in the late twentieth and early twenty-first centuries. These shifts have resulted from advances in technology, reductions in the real costs of travel and growth of international remittance flows as a driving force behind developing economies. The functional relationships between home and host countries have also undergone significant reinterpretation. These global developments form the backdrop against which Japan's contemporary attitudes to immigration must be assessed in order to understand why Japan continues to resist immigration reform in the face of depopulation, demographic change and projected labour shortages. This section will explain these developments in transnational labour movement, 
identifying and exploring two distinct phases of academic theory and policy orientation in the period since the end of the Second World War. The processes of change in migration patterns and policies from the postwar 'long boom' period into the modern globalised era shed light on Japan's failure to engage effectively with the concepts and realities of globalisation.

Differences between 'old' and 'new' theoretical concepts of migration since the Second World War have been characterised in terms of a shift away from straightforward national economic interest perspectives and utilitarian views of migrant labour toward more complex and fully integrated paradigms of migrant labour policy and utilisation. Castles and Miller (1998) identify two distinct phases in the development of transnational labour migration since the end of the Second World War. The first phase spanned the economic 'long boom' period from 1945 to the early 1970s, in which a number of significant organised temporary labour migration programmes (such as Germany's Gastarbeiter programme, and the Bracero programme between the U.S. and Mexico) appeared. It was intended that these programmes would allow large numbers of ostensibly temporary migrants to supplement domestic labour markets in host countries. The first phase came to an end with economic declines that followed the international oil crisis of 1973-4 (p. 67).

The second phase comprises the period from the mid-1970s to the present day. Castles and Miller (1998) argue that change came about as a result of global economic restructuring processes that followed the post-oil crisis recession, eventually combining with technological advances in industry to produce fundamental changes in patterns of world trade and global capital flows (p. 78). Elsewhere, Castles (2002) describes this era as one of "unprecedented social and cultural change" in host countries, brought about in part by the collapse of the international Cold War-era bipolar political structure (pp. 1143-1145). This change has been reflected in the emergence of more extensively multicultural host societies in the developed world. Stalker (2000) also identifies the 1970s oil shocks as a turning point in twentieth century migration, pointing to "political and other processes of globalisation" (p. 26) as propulsive factors in the emergence of new models of population movement.

The evolution of relations between migrant workers and host societies has had important implications for government policymaking around the world. Developed countries have reacted to new migrant mobility by tightening immigration and labour regulations, creating significant political problems around issues of fair representation and human rights 
in liberal democratic societies. Juss (2006) argues that immigration reform attempts around the world have been hampered in the past by an emphasis on the sovereign right of states to exclude migrants, stating that "free movement in law has, if anything, been subject to ever more restrictions in the developed world [in recent times]" (pp. 4-5). A specific example of these tensions can be seen in the refusal of the German government to remove restrictions on migrant workers from Poland until as recently as May 2011, a policy that conflicted with the European Court of Justice's rulings on discriminatory hiring practices within the E.U. (BBC News, 2010a). Zolberg (2000) argues that the instinctive reaction of states at policy level to move toward more closed and restrictive immigration regulations reflects the uncertain status of national sovereignty in the globalised era, claiming that "restrictive immigration regime[s] prevail worldwide because [they] constitute a sine qua non for maintaining the Westphalian international state system as well as the privileged position of the 'core' states and their populations among highly unequal conditions" (p. 62).

The evolution of migration policy since the Second World War was largely dictated in the first instance by 'long boom' era economic assumptions and motivations in host countries that opted to supplement their own domestic labour resources by adopting guest worker programmes. According to Castles (2004), first phase guest worker programmes were essentially founded on a system of neoclassical economic assumptions, in the form of costbenefit calculations on the part of migrants in relation to earning potential in host countries, balanced against the practical ability of host countries to effectively regulate migrant residency and employment conditions (p. 208). A defining economic situation in many countries that introduced guest-worker programmes during this era (particularly European economic powers, such as France and Germany) was a shortage of domestic labour that resulted in very high overall levels of local employment (Stalker, 2000, pp. 28-29). It was assumed that migrant labourers could simply be removed from the labour market in times of recession, with minimal lasting impact on the social fabric of the host country. As Castles (2002) puts it, "no one foresaw enduring flows of migration from increasingly diverse source countries and the resulting emergence of multicultural societies" (p. 1145). For instance, in the case of 1970s recession-era Germany, it was found that immigrants had unexpectedly established social and family ties and networks that brought many more dependant migrants into German society and facilitated overstaying and undocumented employment (Castles \& Miller, 1998, p. 71). Host countries reacted by implementing more stringent and restrictive 
labour migration policies, provoking debate over the feasibility of constructing immigration policies that would meet the economic requirements of host countries without incurring massive social costs and entrenching large underprivileged migrant sub-communities. Zolberg (2000) identifies two competing tendencies in immigration policymaking that appeared as a result of these experiences: The first viewed immigration purely in market economic terms, regarding the flow of migrants (as an economic resource) around the world in the same manner as globalised capital flows and as driven by basic market forces (that is, a view based on the same underlying principles as first phase guest worker programmes). The second reflects a more recent tendency to substantively integrate domestic political stability, social impacts, national identity issues and potential for widespread social disharmony into immigration policy development and debates (p. 62).

With the shortcomings of first phase models in mind, second phase migration models have developed with the goal of integrating solutions to some of the problems described above. Second phase models aim to enhance the effectiveness and sustainability of temporary labour migration by considering effective social integration of migrant workers, development and incorporation of international human rights norms, revised incentive structures intended to minimise migrant overstaying, and management of modern transnational patterns of circular migration. Each of these factors has played a role in thoroughly changing the functions and expected outcomes of labour migration initiatives since the 1970s, both on conceptual and practical levels.

Second phase migration models and policies aim to incorporate social integration measures into immigration policy to a far greater extent than was ever seen in first phase guest worker programmes. Second phase initiatives identify the need to regard effective social integration strategies for migrant workers as an essential component of modern policy formation, and for policymakers to plan for ongoing social and economic effects that might arise from introducing migrant workers into the local labour market. Castles (2004) argues in favour of progressive immigration policy taking a more far-reaching and intensive form than that of past guest worker programmes, claiming that "migration policies may fail if they are based on a short-term view of the migratory process [...] It is necessary to analyse the migratory process as a long-term social process with its own dynamics" (p. 207). Transnational labour migration on a global scale has brought into existence circular or repetitive migration patterns, disproving assumptions that migrants would necessarily settle 
permanently in a specific host country, or embark on a temporary work sojourn in that country with the firm intention of returning home after a certain period (p. 211).

Other areas of change take international norms into account as part of the new reality of migration on a global scale. Castles (2004) argues that recognition of basic human rights now acts to constrain the power of state sovereignty to effectively control migrant labour flows in the manner proposed during the 'long boom' (p. 216). As Sassen (2009) states in the context of migration in Europe: "The institutional development of the European Union and the strengthening of the European Human Rights Court are a partial denationalising of what has historically been constructed as national. [...] This distancing is partially triangulated by some of the E.U. institutions, by the human rights regime, and by the ascendance of transnational civil society". NGO advocacy groups (as described above in the context of Japan) have provided a voice on behalf of migrant communities within host countries' mainstream political discourses - a movement Sassen describes as "the emergence of multiple actors, groups, and communities increasingly keen on broader notions of political membership". Other developments include more substantive recognition of migrants' rights in the legal structure of host countries; as Guiraudon (2000) explains, "scholarly interest in [rights-based] norms [...] re-emerged in the late 1980s as a legitimate competitor to interestbased or power-based explanations in international relations" (p. 1089). In essence, second phase models of migration reject previous policies and theories that saw migrants merely as disempowered units of unskilled labour with little scope to affect host societies beyond their contribution of economic value.

Second phase migration models also aim to address the fundamental problem of migrant overstaying in host countries, which came to be regarded as a central weakness of first phase guest worker programmes. At the end of the 'long boom' era, Germany found that guest workers from Italy, Greece and Turkey had established family connections and social networks in Germany, and were unwilling to return to their home countries when their terms of employment ended. A similar situation undermined the Bracero programme in the U.S., where exploitation of Mexican migrant workers ultimately served to enable subsequent patterns of overstaying, illegal immigration and undocumented migrant employment. Second phase models incorporate a range of policy modifications that aim to alleviate this problem. Basok (2002) points to the Canadian Mexican Agricultural Seasonal Workers' Programme as an example of effective migrant labour management, identifying modifications of policy from 
first phase models that have proved effective in restricting overstaying and undocumented employment to negligible levels. ${ }^{10}$ These include guest worker programme structures that balance the economic interests of employers with workers' rights and the demands of local labour representatives. In comparison, first phase models (specifically the Bracero programme) overemphasised the interests of large and powerful agricultural employers of migrants above all other interest groups (p. 220). According to Basok, guaranteed better conditions for migrants improve working conditions for all labourers (domestic or foreign) in any given industry by minimising the incentives for abuse of vulnerable undocumented workers (p. 221). Basok also emphasises the importance of establishing good relations between employers and workers as a function of policy, thereby minimising incentives for worker abuse and desertion. She argues that deliberate selection of workers who maintain strong family and economic ties with their home countries (in contrast to a policy of hiring workers in desperate circumstances prepared to work for extremely low wages) ensures that migrant workers have economic and sentimental investments in their home countries, reducing the likelihood of indefinite overstaying following conclusion of their employment ( $\mathrm{p}$. 224). Martin (2007) similarly argues in favour of strategic modifications of immigration policy, claiming that "some good could come from [new guest worker programmes], but only if the lessons of the past are understood" (p. 32). Overall, the purpose of policy developments along these lines is to proactively reduce the likely incidence of many social problems associated with overstaying.

Increased awareness of the strategic importance of globalisation in economics and political theory has contributed massively to policy development in second phase migration models. The advent of globalised circular migration has shifted the foundations of past assumptions regarding migrant behaviour, motivations and identity. Developments in technology and the growth of international remittance-sending by migrant workers have redefined the meaning of community membership as well as economic and political participation, in both home and host countries. This has resulted in the formation of what Levitt (2003) refers to as "transnational communities" (p. 262) - that is, expatriate groups that engage actively with social, economic and political affairs in both their home and host

\footnotetext{
${ }^{10}$ Another comparable example of second phase migration policy implemented in the Asia-Pacific region is New Zealand's Recognised Seasonal Employer (RSE) policy (Ramasamy, Krishnan, Bedford, \& Bedford, 2008).
} 
countries. As Levitt (2000) explains, "Increasing numbers of migrants [...] continue to participate in their homelands, even as they are incorporated into host countries. Rather than cutting off their social and economic attachments and trading one political membership for another, some individuals keep feet in both worlds" (p. 459). Globalisation has challenged traditional assumptions about the effects of national borders on transnational political activities, national identity and community identification. Second phase migration models accept the concept of "communities spanning borders" (Levitt, 2000, pp. 460-461), in which migrants enjoy flexibility to move with comparative ease between home and host countries, in contrast to the isolated and disempowered communities otherwise formed within host countries from which individual migrants find, for economic or practical reasons, that there is no incentive to return home. Second phase models propose that host countries opt to implement immigration policies that facilitate stronger individual and communal connections between migrant workers and home countries as a strategy to dissuade undocumented permanent settlement and indefinite overstaying. Correspondingly, second phase models incorporate revised incentive structures in order to attract the right kinds of temporary migrant labour, entailing acceptance of a permanent 'cyclical' migrant community presence. As Basok (2002) argues, this goal can be achieved by selecting and supporting migrants that retain strong incentives to remain actively involved in the economic and social affairs of their home countries.

In the case of first phase guest worker programmes, the central priority of immigration policy (from the perspective of host countries) was to supplement an already fully-employed workforce in order to maximise industrial output and contain labour costs and inflation (Stalker, 2000, p. 28). The need for greater numbers of workers in Europe in that era was also partly due to the loss of a generation of working-age people in the Second World War. In contrast, a key purpose of second phase migration models today is to secure substantial replacement workforces to make up for labour shortfalls in those highlydeveloped economies suffering under the economic burdens of ageing and depopulation. It is important to discern that current labour shortfalls in highly-developed depopulating countries originate not from full domestic employment, but from a scarcity of working-age people. Shifts toward domestic employment in service sectors and away from the heavy industries that drove western (and Japanese) economic development prior to the 1970s have starved crucial economic sectors of labour resources. In Japan's case, calls for immigration reform on 
the massive scale proposed by the LDP's Hidenao Nakagawa in 2008 demonstrate recognition of a need to recruit 'replacement' labour from abroad to make up for inevitable declines in the number of Japanese workers available and willing to work in Japan's primary industries (Matsutani, 2008). Castles and Miller (1998) note the difficult position that confronts Japanese policymakers with regard to managing opposing pressures of tight immigration control and labour market stagnation; they identify "a contradiction between officially-stated aims of migration control and the tacit acceptance of undocumented inflows which meet labour market needs: this applies [...] to current policies of several Asian labourimporting countries" (pp. 93-94).

This latter point summarises the substance of immigration policy in Japan at present: Japan's policymakers have yet to effectively engage with the globalisation of migration since the 1970s. Japan's binary 'us-and-them', 'insider-outsider' conceptualisation of world affairs has struggled to adapt to new realities of twenty-first century globalised population movement and community membership. By restricting and compartmentalising migrants, Japan has been unable to effectively capitalise on modern globalised patterns of labour movement. For the same reason, Japan has been unwilling to implement policy reforms that would minimise potential for overstaying by allowing unskilled migrants to build and maintain strong economic and sentimental connections both with Japan and with their countries of origin.

Japan's ongoing official tolerance of "the 'back door' of irregular labour migration" (Castles, 2004, p. 216) runs counter to the projections and policy recommendations of second phase migration models. The current government policy platform on immigration, the Third Basic Plan for Immigration Control, persists with an inflexible policy principle of 'no unskilled workers accepted', and demonstrates little apparent recognition of Japan's impending need for a revitalised working-age population. However, it must be noted that the Third Basic Plan does allow for de-facto undocumented employment of migrant workers in Japan outside the constraints of regulatory oversight. Japan's current immigration regime facilitates the practice of hiring migrants abroad to enter Japan under the guise of 'trainee' and 'intern' employment programmes, producing a source of cheap labour for favoured industries without providing recognition or legal protections afforded to regular migrants that enter the country on conventional work visas (Solidarity Network with Migrants Japan, 2007). Continued tolerance for these irregular sources of migrant labour suggests policymakers still 
view the interests of Japan's economy and society in accordance with a policy framework that regards workers in terms of simple units of labour. Basok (2002) refers to the limitations of this view in relation to the experience of guest workers in the U.S. by pointing to employment contract violations, overworking, inadequate accommodation and other forms of worker exploitation as just a few of the outcomes to be expected from persisting with such a policy (pp. 225-226). Similar conditions have been observed in officially sanctioned 'trainee' employment programmes in Japan. In particular, media commentators have highlighted instances from Japan's 'trainee' programmes where workers were forced to work in unsafe conditions, placed in substandard accommodation, had their passports confiscated and pay withheld, and suffered high rates of injury and death due to overwork (Tabuchi, 2010). Stephen Castles (2004) asks, "Why does the Japanese government not take effective measures to stop employment of undocumented workers? Administrative weakness does not seem to be a major reason. Nor is ignorance, when a casual observer can find streets where illegal day-labourers are hired by contractors every morning" (pp. 215-216). It seems that by persisting with policies that refuse migrant workers the protections of Japan's labour laws (although these 'trainees' are unofficial guest workers in all but name), policymakers reveal an attitude to migration that has much more in common with first phase models described above than with contemporary second phase models.

This interpretation is further strengthened in review of Nikkei migrant worker treatment under Japan's 'special permanent resident' visa regime. The 2008 recession-era policy encouraging Nikkei workers to return to their home countries in Latin America can be compared to planned compulsory removal of migrant workers under first phase guest worker models in Europe, where policymakers intended for migrant workers to be "recruited, utilised and sent away again as employers required" (Castles \& Miller, 1998, p. 71). Overall, the Nikkei experience serves to expose the motivations of policies that evidently regard Nikkeijin as mere de-facto guest workers along the same lines as migrant workers in the first phase German Gastarbeiter model. Japan's 'special permanent resident' immigration scheme has now generally come to be viewed as a failure because of labour and immigration policies "that ignored integration and assimilation" (Arudou, 2009).

Contemporary Japanese immigration policy falls into the conceptual gap between recognised failure of first phase temporary labour migration schemes, and proposed reforms of second phase models. In essence, Japan's binary 'us-and-them' policy approach has 
prevented Japanese policymakers from substantively engaging with second phase models of migration. Instead of striving to develop and adopt innovative strategies to integrate new legitimate migrant workers into Japan's labour market, policymakers remain preoccupied with concerns of overstaying and the formation of undocumented foreign sub-communities. As discussed above, the primary cause of this preoccupation is an institutionalised fear of the political consequences of redefining Japan's social makeup and national discourse of identity. In effect, Japan's current immigration policies facilitate and encourage exactly those mostfeared outcomes - overstaying, illegal employment, migrant worker abuse, and inevitable associations of migrants with crime as a result of visa and residency violations. Meanwhile, political opposition to integration-based immigration reform remains very high. Essentially, Japan's rigid 'us-and-them' policy orientation compels policymakers to respond to Japan's demographic crisis and ageing society with a range of immigration policies that have already proven to be destructive failures elsewhere. As a result, there is perhaps little reason to believe that Japan will respond decisively to the economic and social consequences of depopulation and aging until profound changes occur in policymakers' conceptions of the nature of Japan's national identity and role in the wider global community. A philosophical change away from 'us-and-them' views of world affairs must be seen as a precondition to Japan's successful adoption of second phase migration models, since the conceptual heart of those models is broad acceptance of universalised global values and norms, which in turn rely on willing acknowledgement of, investment in and engagement with other global actors and with the modern globalised system as a whole. 


\section{CHAPTER 5: CONCLUSION}

I return now to the initial question posed at the beginning of this work: Why does Japan resist taking the necessary steps to introduce immigration and citizenship reforms that could help to alleviate the negative economic impact of population decline? The previous chapter has outlined the two key parts of my response to this question. These relate to the binary 'usand-them' mindset of Japan's policymakers, and the failure of Japan to engage effectively with new labour migration models that have emerged from a growing acceptance around the world of globalised norms and evolving transnational identities in the twenty-first century.

My interpretation in this work differs from conventional responses to the question, as outlined in Chapter Three. Arguments that link Japan's attitudes to racism and xenophobia on the one hand, and belief in social homogeneity on the other, draw attention to important single aspects of Japan's stance on immigration. However, they fail to specifically explain why Japan resolutely refuses to accept migrant workers while facing the onset of dire economic and demographic consequences of depopulation. That is to say, conventional analyses do not explain why Japan's demographic crisis has not created sufficient incentives for substantive policy change.

I have argued that Japan resists immigration reform because policymakers continue to base immigration policies around a series of assumptions first established in the immediate postwar period, when Japan adopted the Yoshida Doctrine and laid the groundwork for economic expansion. As its economy approached maturity in the 1970s and 1980s, Japan sought to employ migrant labourers without adapting the fundamental social and economic assumptions upon which the country's economic success was initially built. These assumptions essentially match those of first phase labour migration theories; they are based on utilisation of migrant labour with little regard given to social integration of the migrants themselves. As a consequence, Japan's policies today make no real allowance for strategic proactive social integration. The outcome of this has been the creation of an underclass of undocumented workers, migrant overstaying, exploitation by employers, and discrimination against migrants. These outcomes largely mirror the experience of Germany, the U.S. and other host countries that applied similar assumptions to their own postwar migrant worker schemes. Japan's response to these outcomes has been to put greater emphasis on policing 
migrant communities and cracking down on overstayers. Decisive action has yet to be taken to deal with the root causes of overstaying and undocumented employment.

Academic theory and practical experience elsewhere suggest that Japan could benefit by implementing reforms associated with second phase labour migration policies. These reforms include greater recognition of migrant worker rights, more fluidity in migration flows, strategic selection of migrants (rather than simply hiring those willing to work for the lowest wages), and efforts to promote more widespread acceptance of multiculturalism in Japanese society. Reforms of this nature would soften the blunt, uncompromising 'inside/outside' dichotomy of current mainstream interpretations of Japanese national identity, and would allow Japan to become more responsive to globalised trends and developments. Crucially, they would also allow policymakers a far greater degree of flexibility in sourcing and managing labour from abroad as a response to demographic decline and depopulation.

However, Japan has been prevented from implementing this kind of reform agenda because rigid 'inside/outside' social structures remain an entrenched feature of Japan's social policies. These structures sustain an ideology of social homogeneity against multicultural pressures, and allow politicians and bureaucrats to consolidate popular support and legitimacy in a time of economic decline and high unemployment. They also act as justification for bureaucratic persistence with the status-quo in economic policy and governance. They are built on institutionalised distrust of 'the other' in government and society, and manifest in a series of policies that are firmly oriented toward keeping nonJapanese influence at arm's length.

It is important to understand the reasons why Japan's policymakers adhere to such a viewpoint. I have argued here that Japan's binary, 'us-and-them' mindset is a product of historical, practical, cultural and political factors. Historical experiences of interaction with foreigners created a distrust of 'non-Japanese' actors that endures in government and society today. Practical implementation of immigration policy reinforces a self-fulfilling cycle of migrant failure to integrate with mainstream society, as migrants face overwhelming disadvantages in labour regulations and the workplace. This forms the basis of justifications for further exclusion of migrants from the labour market in Japan, and disincentivises hiring of migrant workers, even in those employment sectors suffering critical labour shortages. Failure to integrate is then used by politicians and bureaucrats as part of populist political 
strategies to gain public support and to further marginalise migrants from mainstream society, thereby helping to rationalise the ideology of social homogeneity upon which policymaking in contemporary Japan is based.

It is likely that Japan will have difficulty in adopting second phase immigration policies without also precipitating major changes in discourses of national identity. For example, Levitt's conceptualisation of 'transnational communities' (as described in Chapter Four) is fundamentally incompatible with Japan's current monoethnic and monocultural ideology because it demands a more ambiguous and flexible notion of national borders and community membership than current policy attitudes in Japan allow. The logic of second phase migration policy prescriptions only makes sense if one accepts the value of openness and engagement with globalised systems and communities, rejecting a competitive zero-sum conception of interactions between national communities on the world stage. However, Japan's binary, 'usand-them' view of world affairs compels policymakers to persist with precisely that kind of competitive conception. That is to say, Japan's binary mindset - perceiving Japan to be at odds with other nations collectively - necessarily conflicts with the idea of global communities and systems.

In summary, the purpose of my analysis has been to explain how unfavourable social effects and outcomes of current policies (such as overstaying, undocumented employment and exploitation of migrants) serve to justify ongoing resistance to immigration reform in Japan, in spite of demographic decline and depopulation. Policymakers have fundamentally misunderstood how their policies have been responsible for producing many of these negative social effects and outcomes. However, an alternative policy orientation (that of second phase migration models) remains inaccessible to policymakers because the foundation of second phase models - open engagement with global communities and systems - is incompatible with the binary, 'us-and-them' mindset that continues to influence public policymaking in Japan. In essence, Japan persists with restrictive immigration policies because there is no better alternative available under present political conditions. A more effective alternative cannot be implemented until profound shifts occur among governing elites in perceptions of Japan's national identity and role in the global community.

So what are the implications of these conditions for Japan's future? The relevance and practicality of Japan's mindset is now challenged by emerging globalised systems that break 
down many traditional assumptions about national interests and identity. Japan's inwardlyoriented approach to politics, economics and social issues served the country well in the period during which it developed from an impoverished postwar state to a world-leading economic power. However, monoethnic and monocultural values have served Japan poorly in terms of facilitating mutually-beneficial integration with other countries, cultures and economies. Such integration is a cornerstone of effective participation within the globalised world political economy of the early twenty-first century. Japan's ongoing reluctance to accept migrants is symptomatic of a desire to maintain successful policy formulas of the past in spite of their steadily decreasing tenability in a present-day globalised context.

I have argued that Japan's binary 'us-and-them' view of interaction with the rest of the world is incompatible with effective engagement with global communities and systems. Instead of investing politically in globalised labour migration initiatives with other stakeholders around the world, Japan's worldview isolates the country from benefits of global collective action and coordination. One of these benefits is emerging transnational population movement that connects willing labourers in developing countries with highly-developed economies that need new sources of working-age people in order to maintain high levels of economic productivity and to support burgeoning elderly and retired populations. By creating so many formal and informal restrictions on non-Japanese migrant labourers, Japanese policymakers have produced artificial disincentives for the most desirable and productive kinds of foreign workers to even consider Japan as a working destination.

The basic reasons for Japan's disinclination to participate in globalised trends originate from social ideology that developed to suit the demands of a very different era and set of economic circumstances. Ideas of Japanese monoethnicity, monoculturality and 'harmony' aided industrial recovery in the postwar period by replacing wartime ideologies of militarism and ultranationalism as sources of national identity and unification (Van Wolferen, 1989, pp. 263, 267). This new ideology of social homogeneity contradicted Japan's own long history of regional cultural and linguistic variation, but served the purpose of establishing a strong unified workforce that helped to enable massive industrial growth in Japan during the postwar economic 'long boom' period. Japanese isolationism, fear of 'the other' and political activism against migrants would perhaps have been less able to maintain traction in Japanese politics and society today without promotion of a collectivised view of the world outside Japan as an economic competitor (Van Wolferen, 1989, pp. 377-378). In this way, the idea 
that migrants represent a threat to national 'harmony' has remained an enduring social byproduct of the economic compulsions of a previous era.

In short, it can be argued that Japan persistently refuses to accept migrants today because of immigration and labour policies that are simply behind the times. The future inclination of political and bureaucratic leaders may very well be to persist with current policies and social views that deliberately insulate Japan from developing global norms and trends. The implication of this strategy is that by continuing further along the path of isolation and minimisation of contact with the global community, policymakers are likely to hasten the onset of the worst effects of demographic decline and depopulation. Whether that outcome will eventually lead Japan toward a new era of national self-examination and social inclusiveness, or to a progressively-hardening radical isolationism, remains to be seen. Discussion of immigration reform is thus tied intrinsically to discussion of Japan's future national and cultural identities.

The primary purpose of this work has been to investigate why policymakers remain reluctant to reform Japan's strict immigration regulations. Nevertheless, the question of how Japan could or should respond to the crisis also deserves brief consideration here. Policymakers today remain highly constrained by the principle of "no unskilled labour accepted' contained in the Third Basic Plan for Immigration Control. That inflexibility has discouraged debate over alternative policy proposals that involve the use of migrant labour, even on a theoretical or hypothetical basis. If that central principle of the Third Basic Plan were to be modified to permit discussion of how migrants might best be integrated into Japan's society and economy in the future, progress could be made toward developing innovative solutions without immediately coming into conflict with the principles that currently define Japan's social policies. Change of this nature would necessarily represent a profound departure from Japan's policymaking orthodoxy, and could create new opportunities to develop relevant and effective immigration policies that respond more realistically to Japan's current demographic and economic situation.

Constructive debates addressing the utility of migrant labour in Japan under a newly liberalised immigration regime could also facilitate greater policy engagement with the global economy and community in other areas. Such a development might renew public conversation over Japan's national priorities in the globalised era. 
But how likely are Japan's policymakers to pursue meaningful change? As pressing as the problem of population decline may appear, little urgency is evident on the part of politicians and bureaucrats to carry out decisive reforms before the economic effects of depopulation become impossible to ignore. Research outcomes on the willingness of the Japanese public to tolerate a greater migrant presence have produced mixed indications: Llewelyn and Hirano (2009) argue that public acceptance of a multicultural future for Japanese society is measurably increasing, particularly among Japan's younger generations. In contrast, Tabuchi (2011) points to public opinion polls conducted in 2008 that found 65 percent of respondents opposed immigration reform, irrespective of the effects of depopulation (p. 2). Though the negative impacts of the demographic crisis are increasingly being felt in Japanese society, Tabuchi concludes that "Tokyo seems to have resigned itself to a demographic crisis that threatens to stunt the country's economic growth [...] and bankrupt its social security system" (p. 1). As long as Japan remains in a state of low economic growth and high unemployment, it seems unlikely for political reasons that policymakers will be motivated to implement immigration reforms. For this reason, changes in the approach to immigration may ultimately become tied to broader patterns of generational change in Japanese society and politics in the twenty-first century.

Japan's demographic crisis and policy responses have important implications for further research into demographic decline in highly-developed countries. While Japan is at the leading edge of population decline as a social and economic issue, several other industrialised nations in Asia and Europe face similar demographic predicaments. Japan is an important contributor to the wider problem of population decline in Pacific Asia as a whole. Jones, Straughan and Chan (2009) categorise Japan together with the Republic of Korea, Singapore and Taiwan as a group of Pacific Asian countries that suffer some of the lowest fertility rates seen anywhere in the world, and argue that these countries must increase fertility in order to ensure future economic sustainability (p. 5). These scholars propose that managed migration could effectively make up for population shortfalls in Pacific Asian countries, provided that fertility can be raised from current rates to levels closer to adequate population replacement rates (p. 17). This argument raises interesting possibilities for development of an interactive theoretical model that directly connects existing fertility growth initiatives to immigration policy reform in order to alleviate the effects of demographic decline. The function of this model would be to indicate how migrant labour might be utilised strategically to allow time 
for 'pro-natalist' policies (Jones, et al., 2009, p. 3) to take effect. However, such a model would naturally be dependent on effective concurrent reversal of downward fertility trends in these countries. Further investigation into the parameters of an interactive 'fertility/migration' model would contribute substantially to existing academic literature on the subject of depopulation in highly-developed countries.

Several highly-developed European countries also currently face pressing questions of how best to alleviate demographic decline in the twenty-first century. Germany, Italy, Sweden and Switzerland all suffer from high national median ages at levels comparable to that of Japan (United Nations, 2002, p. 17). Fertility rates in Northern and Western Europe have also declined well below replacement level since the 1970s (d'Addio \& d'Ercole, 2005, p. 12). However, European approaches to social implications of depopulation differ markedly to those of Japan. For example, Soysal (2010) highlights universal values and tolerance of ethnic and cultural diversity as part of France's recent discourse of national identity, as expressed in the national school history curriculum. That discourse acknowledges the diminishing stature of sovereignty relative to national identity, in favour of a pre-eminence of universalised human rights (p. 100). In Germany, cancellation of the Gastarbeiter programme in the mid-1970s gave rise to public debate over the ongoing social effects of a new multiculturalism in German society. One prominent thread of policy discussion in the 1980s was that Germany's policymakers might proactively engage with poorer countries as part of strategies to promote economic development abroad and to incentivise migrant worker return (Teitelbaum \& Winter, 1985, pp. 126-127).

From these examples, it can be seen that highly-developed European countries face a similar need to establish policy structures that successfully balance demographic concerns with cultural debates over the impact of depopulation and labour migration on national identity. The critical point of difference between these countries and Japan is that institutionalised engagement with the E.U. has allowed most European countries opportunities and incentives to incorporate transnational population movement into modern conceptions of national identity. For this reason, forthcoming responses of policymakers in E.U. countries to demographic change are likely to be very different to those seen in Japan. The framework for these responses can already be seen in the European Commission Policy Plan on Legal Migration, a policy platform that tries to build the foundation of common - or at least coordinated - Europe-wide policies on highly skilled and seasonal workers, as well as 
paid trainees. This platform is intended to "enhance the integration of legally residing immigrants in the E.U. by ensuring their fair treatment" (European Commission, 2007).

Demographic decline and depopulation are likely to further evolve into urgent social and economic issues for highly-developed countries in the twenty-first century. The aforementioned examples of countries from Europe and Pacific Asia demonstrate how specific social and political conditions associated with depopulation differ considerably from region to region. However, assessment of Japan's immigration policies raises the question of what other countries can learn from Japan's current policy weaknesses. I contend that Japan's immigration policies best serve to illustrate the dangers of persisting with policy strategies that may have worked well in the past, but that have since been overtaken by domestic and global political developments. The greatest benefit of studying Japan's demographic crisis from the perspective of other highly-developed countries may ultimately be to assist in developing responsive, flexible 'best practice' immigration policy structures that effectively combine the economic and social priorities of those nations with furtherance of the interests and life prospects of migrants.

At its core, Japan's demographic crisis represents a critical historical juncture. The situation invites broad reinterpretation of Japan's role in the world from the perspectives of domestic and foreign scholars of Japan, and from Japanese society itself. It is possible that the developing effects of the crisis will serve as a catalyst for reinvigorated discussion of the foundational values of Japan in the twenty-first century, and as an opportunity to redefine Japan's national goals and identity in accordance with the existence of global communities and systems beyond Japan's shores. By engaging more closely and cooperating with other countries and communities over the problem of depopulation, Japan would be in a position not only to alleviate its own demographic crisis, but to play a valuable role in establishing policy precedents that reduce the likelihood of other countries having to endure the same difficulties that Japan currently faces. As I have argued throughout this work, such an outcome depends largely on whether Japan's policymakers can move away from a binary, 'us-and-them' conception of the world. It remains to be seen whether demographic decline and the economic consequences of depopulation ultimately provide the motivation needed for this outcome to occur. 


\section{BIBLIOGRAPHY}

Allen, M. (2009). Okinawa, ambivalence, identity, and Japan. In M. Weiner (Ed.), Japan's minorities: The illusion of homogeneity (pp. 188-205). London; New York: Routledge.

Arakaki, O. (2008). Refugee law and practice in Japan. Aldershot: Ashgate.

Arudou, D. (2004, March 30). Downloadable discrimination. The Japan Times. Retrieved from http://search.japantimes.co.jp/member/member.html?fl20040330zg.htm

Arudou, D. (2009, April 7). 'Golden parachutes' mark failure of race-based policy. The Japan Times. Retrieved from http://search.japantimes.co.jp/cgi-bin/fl20090407ad.html

Arudou, D. (2010a, October 5). Census blind to Japan's true diversity. The Japan Times. Retrieved from http://search.japantimes.co.jp/cgi-bin/fl20101005ad.html

Arudou, D. (2010b, April 6). Japan, U.N. share blind spot on 'migrants'. The Japan Times. Retrieved from http://search.japantimes.co.jp/cgi-bin/fl20100406ad.html

Basok, T. (2002). He came, he saw, he stayed: Guest worker programmes and the issue of non-return. International Migration, 38(2), 215-238.

BBC News. (2009). Japan's retired doctors help elderly. Retrieved from http://news.bbc.co.uk/2/hi/asia-pacific/8089288.stm

BBC News. (2010a). Germany chided for limit on Poles. Retrieved from http://news.bbc.co.uk/2/hi/europe/8473074.stm

BBC News. (2010b). Japan may pick robots over immigrants. Retrieved from http://news.bbc.co.uk/2/hi/business/8687196.stm

BBC News. (2010c). Profile: Ichiro Ozawa. Retrieved from http://www.bbc.co.uk/news/world-asiapacific-11284634

Befu, H., \& Manabe, K. (1990). Empirical status of Nihonjinron: How real is the myth? In A. Boscaro, F. Gatti \& M. Raveri (Eds.), Rethinking Japan, volume II: Social sciences, ideology and thought (pp. 124-133). London: Japan Library Limited.

Benedict, R. (1946). The chrysanthemum and the sword. Tokyo: Charles E. Tuttle Company.

Bermingham, J. R. (2001). Immigration: Not a solution to problems of population decline and aging. Population and Environment, 22(4), 355-363.

Buckley, R. (1990). Japan today (2 ed.). Cambridge; New York: Cambridge University Press.

Castles, S. (2000). Ethnicity and globalization: From migrant worker to transnational citizen. London: Sage Publications. 
Castles, S. (2002). Migration and community formation under conditions of globalization. International Migration Review, 36(4), 1143-1168.

Castles, S. (2004). Why migration policies fail. Ethnic and Racial Studies, 27(2), 205-227.

Castles, S., \& Miller, M. J. (1998). The age of migration: International population movements in the modern world. New York; London: The Guilford Press.

Chamberlain, B. H. (1890). Things Japanese: Being notes on various subjects connected with Japan, for the use of travelers and others. Rutland, VT: Charles E. Tuttle Company.

Chamberlain, B. H. (1971). Things Japanese: Being notes on various subjects connected with Japan, for the use of travelers and others. Rutland, VT: Charles E. Tuttle Company.

Chiswick, B. R., \& Hatton, T. J. (2005). International migration and the integration of labor markets. In M. D. Bordo, A. M. Taylor \& J. G. Williamson (Eds.), Globalization in historical perspective (pp. 65-120). Chicago: University of Chicago Press.

Chung, E. A. (2010). Immigration and citizenship in Japan. New York: Cambridge University Press.

Clammer, J. (2001). Japan and its others. Melbourne: Trans Pacific Press.

Clark, G. (2009, March 24). Barring the people needed. The Japan Times. Retrieved from http://search.japantimes.co.jp/cgi-bin/eo20090324gc.html

Coulmas, F. (2007). Population decline and aging in Japan: The social consequences. London, New York: Routledge.

d'Addio, A. C., \& d'Ercole, M. M. (2005). Trends and determinants of fertility rates in OECD countries: The role of policies. Paris: Organisation for Economic Co-operation and Development.

Dale, P. N. (1986). The myth of Japanese uniqueness. London: Croom Helm.

Douglass, M., \& Roberts, G. S. (Eds.). (2003). Japan and global migration: Foreign workers and the advent of a multicultural society. Honolulu: University of Hawai'i Press.

Eubank, D. (2010, July 20). Immigration procedures face huge shakeup. The Japan Times. Retrieved from http://search.japantimes.co.jp/cgi-bin/fl20100720zg.html

European Commission. (2007). A comprehensive European migration policy. Brussels: European Commission.

Fackler, M. (2010, August 28). New dissent in Japan is loudly anti-foreign. The New York Times. Retrieved from http://www.nytimes.com/2010/08/29/world/asia/29japan.html?_r=2\&scp=1\&sq=japan\%20 far\%20right\&st=cse

Gooday, G. J. N., \& Low, M. F. (1998). Technology transfer and cultural exchange: Western scientists and engineers encounter late Tokugawa and early Meiji Japan. Osiris, 13(Beyond Joseph Needham: Science, technology and medicine in East and Southeast Asia), 99-128. 
Goodman, R. (2003). The changing perception and status of Japan's returnee children (kikokushijo). In R. Goodman, C. Peach, A. Takenaka \& P. White (Eds.), Global Japan: The experience of Japan's new immigrant and overseas communities (pp. 177-194). London; New York: RoutledgeCurzon.

Guiraudon, V. (2000). European courts and foreigners' rights: A comparative study of norms diffusion. International Migration Review, 34(4), 1088-1125.

Hardacre, H. (1989). Shinto and the state, 1868-1988. Princeton, NJ: Princeton University Press.

Harlan, C. (2010, July 28). Strict immigration rules may threaten Japan's future. The Washington Post. Retrieved from http://www.washingtonpost.com/wpdyn/content/article/2010/07/27/AR2010072706053.html

Hearn, L. (1894). Glimpses of unfamiliar Japan. Boston: Houghton, Mifflin and Company.

Hongo, J. (2010, June 2). Hatoyama quits as prime minister. The Japan Times. Retrieved from http://search.japantimes.co.jp/cgi-bin/nn20100602x1.html

Ito, M. (2008, June 7). Diet officially declares Ainu indigenous. The Japan Times. Retrieved from http://search.japantimes.co.jp/cgi-bin/nn20080607a1.html

Jeans, R. B. (2005). Victims or victimizers? Museums, textbooks, and the war debate in contemporary Japan. The Journal of Military History, 69(1), 149-195.

Jones, G., Straughan, P. T., \& Chan, A. (Eds.). (2009). Ultra-low fertility in Pacific Asia: Trends, causes and policy issues. London; New York: Routledge.

Jordan, B., \& Duvell, F. (2003). Migration: The boundaries of equality and justice. Cambridge: Polity Press.

Juss, S. S. (2006). International migration and global justice. Aldershot, Hampshire: Ashgate.

Kazui, T., \& Videen, S. D. (1982). Foreign relations during the Edo period: Sakoku reexamined. Journal of Japanese Studies, 8(2), 283-306.

Kelly, T. (2009). The 800-pound immigration gorilla. Forbes. Retrieved from http://www.forbes.com/2009/08/22/japan-election-immigration-Idp-jdp-tokyodispatch.html

Kerr, A. (2001). Dogs and demons: Tales from the dark side of Japan. New York: Hill and Wang.

Koizumi, K. (1992). Refugee policy formation in Japan: Developments and implications. Journal of Refugee Studies, 5(2), 123-135.

Larimer, T. (2000). Rabble rouser. Time Asia, 155(16). Retrieved from http://cgi.cnn.com/ASIANOW/time/magazine/2000/0424/cover1.html 
Levitt, P. (2000). Migrants participate across borders: Toward an understanding of forms and consequences. In N. Foner, R. G. Rumbaut \& S. J. Gold (Eds.), Immigration research for a new century: Multidisciplinary perspectives (pp. 459-479). New York: Russell Sage Foundation.

Levitt, P. (2003). Transnational villagers. In J. Stone \& D. Rutledge (Eds.), Race and ethnicity: Comparative and theoretical approaches (pp. 260-274). Oxford: Blackwell Publishing.

Lie, J. (2001). Multiethnic Japan. Cambridge, Mass.: Harvard University Press.

Llewelyn, J., \& Hirano, J. (2009). Importing human capital: Contemporary Japanese attitudes to immigration. Electronic Journal of Contemporary Japanese Studies. Retrieved from http://www.japanesestudies.org.uk/articles/2009/Llewelyn.html

Machimura, T. (2003). Local settlement patterns of foreign workers in Greater Tokyo: Growing diversity and its consequences. In M. Douglass \& G. S. Roberts (Eds.), Japan and global migration: Foreign workers and the advent of a multicultural society (pp. 176-195). Honolulu: University of Hawai'i Press.

Martin, P. (2007). Be my guest worker? The American Interest, 2(3), 32-41.

Masters, C. (2009). Japan to immigrants: Thanks, but you can go home now. Time, 173(16). Retrieved from http://www.time.com/time/world/article/0,8599,1892469,00.html

Matsutani, M. (2008, June 19). Radical immigration plan under discussion. The Japan Times. Retrieved from http://search.japantimes.co.jp/cgi-bin/nn20080619f1.html

Matsutani, M. (2009, July 1). Visa overstayers given too many breaks: Rightist. The Japan Times. Retrieved from http://search.japantimes.co.jp/cgi-bin/nn20090701a3.html

Nippon Keidanren. (2004). Recommendations on accepting non-Japanese workers. Tokyo: Nippon Keidanren (Japan Business Federation).

OECD. (2007). Can policies boost birth rates? Paris: Organisation for Economic Co-operation and Development.

OECD. (2009). Japan: Highlights from OECD pensions at a glance. Paris: Organisation for Economic Co-operation and Development.

OECD. (2010). Recent changes in migration movements and policies (country notes): Japan. Paris: Organisation for Economic Co-operation and Development.

OECD/Korea Policy Centre. (2009). Key findings: Japan. Seoul: Organisation for Economic Cooperation and Development.

Ogawa, N., \& Retherford, R. D. (1997). Shifting costs of caring for the elderly back to families in Japan: Will it work? Population and Development Review, 23(1), 59-94.

Ogawa, N., Retherford, R. D., \& Matsukura, R. (2009). Japan's declining fertility and policy responses. In G. Jones, P. T. Straughan \& A. Chan (Eds.), Ultra-low fertility in Pacific Asia: Trends, causes and policy issues (pp. 40-72). London; New York: Routledge. 
Ohno, T. (2001). Japanese warming to foreign residents with conditions. The Asahi Shimbun Asia Network. Retrieved from http://www.asahi.com/english/asianet/report/eng_2001_33.html

Pascale, R. T., \& Athos, A. G. (1981). The art of Japanese management: Applications for American executives. New York: Simon and Schuster.

Perez, L. G. (1998). The history of Japan. Westport, CT: Greenwood Press.

Prestowitz, C. V. (2010). Lie of the tiger. Foreign Policy, 182, 34-37.

Pyle, K. B. (1983). Japan besieged: The textbook controversy: Introduction. Journal of Japanese Studies, 9(2), 297-300.

Ramasamy, S., Krishnan, V., Bedford, R., \& Bedford, C. (2008). The Recognised Seasonal Worker policy: Seeking the elusive triple wins for development through international migration. Pacific Economic Bulletin, 23(3), 171-186.

Reed, A. (2008). Canada's experience with managed migration. International Journal, 63(2), 469-485.

Reischauer, E. O. (1988). The Japanese today. Cambridge, Mass.: Harvard University Press.

Sakanaka, H. (2010, May 26). Japan must become 'immigration powerhouse'. The Daily Yomiuri. Retrieved from http://www.yomiuri.co.jp/dy/columns/commentary/20100526dy01.htm

Sakuragawa, M., \& Makino, T. (2007). Labor force ageing and economic growth in Japan. In K. Hamada \& H. Kato (Eds.), Aging and the labor market in Japan: Problems and policies (pp. 57-74). Cheltenham, UK: Edward Elgar.

Sassen, S. (1994). Economic internationalization: The new migration in Japan and the United States. Social Justice, 21(2), 62-83.

Sassen, S. (2009). Membership and its politics: When the outsider expands the formal rights of citizens. European Alternatives. Retrieved from http://www.euroalter.com/2009/saskiasassen-membership-and-its-politics/

Sawamura, N. (2002). Local spirit, global knowledge: a Japanese approach to knowledge development in international cooperation Compare, 32(3), 339-348.

Shibuichi, D. (2007). The 'uyoku ronin do': Assessing the lifestyles and values of Japan's contemporary right wing radical activists. Electronic Journal of Contemporary Japanese Studies. Retrieved from http://japanesestudies.org.uk/discussionpapers/2007/Shibuichi.html

Shimizu, K. (2008, February 13). Okinawa rape case sparks resentment. The Japan Times. Retrieved from http://search.japantimes.co.jp/cgi-bin/nn20080213a1.html

Shipper, A. W. (2008). Fighting for foreigners: Immigration and its impact on Japanese democracy. Ithaca: Cornell University Press. 
Solidarity Network with Migrants Japan. (2007). Living together with migrants and ethnic minorities in Japan: NGO policy proposals. Tokyo: Solidarity Network with Migrants Japan (SMJ).

Soysal, Y. N. (2010). Reconceptualizing the republic: Diversity and education in France, 1945-2008. Journal of Interdisciplinary History, 41(1), 97-115.

Stalker, P. (2000). Workers without frontiers: The impact of globalization on international migration. Geneva: International Labour Office.

Statistics Bureau Japan. (2010). Statistical handbook of Japan 2010. Tokyo: Ministry of Internal Affairs and Communications.

Szymkowiak, K., \& Steinhoff, P. G. (1995). Wrapping up in something long: Intimidation and violence by right-wing groups in postwar Japan. Terrorism and Political Violence, 7(1), 265-298.

Taberner, P. (2008, July 16). An immigration conundrum in Japan. The Asia Times Online. Retrieved from http://www.atimes.com/atimes/Japan/JG16Dh01.html

Tabuchi, H. (2009, February 21). When consumers cut back: An object lesson from Japan. The New York Times. Retrieved from http://www.nytimes.com/2009/02/22/business/worldbusiness/22japan.html?_r=1\&fta=y

Tabuchi, H. (2010, July 20). Japan training program is said to exploit workers. The New York Times. Retrieved from http://www.nytimes.com/2010/07/21/business/global/21apprentice.html

Tabuchi, H. (2011, January 2). Japan curbs hiring foreigners even as labor shortage looms. The New York Times. Retrieved from http://www.nytimes.com/2011/01/03/world/asia/03japan.html?pagewanted=1\&tntemail1= $y \&$ \& $=1 \&$ emc $=$ tnt

Teitelbaum, M. S., \& Winter, J. M. (1985). The fear of population decline. Orlando: Academic Press.

The Japan Times. (2005, December 5). Venues face stricter rules for foreign entertainers. Retrieved from http://search.japantimes.co.jp/cgi-bin/nn20051205a3.html

The World Bank. (1994). Averting the old age crisis: Policies to protect the old and promote growth. Washington DC: The World Bank.

United Nations. (2002). World population ageing 1950-2050. New York: United Nations Department of Economic and Social Affairs.

Van Wolferen, K. (1989). The enigma of Japanese power: People and politics in a stateless nation. New York: A. A. Knopf.

Vogel, E. F. (1979). Japan as number one: Lessons for America. Cambridge, Mass.: Harvard University Press

Watanabe, O. (1997). The weakness of the contemporary Japanese state. In J. Banno (Ed.), The political economy of Japanese society [online] (pp. 109-161). Oxford; New York: Oxford University Press. 
Wattenberg, B. J. (2004). Fewer: How the new demography of depopulation will shape our future. Chicago: Ivan R. Dee.

Winter-Ebmer, R., \& Zweimuller, J. (1999). Do immigrants displace young native workers: The Austrian experience. Journal of Population Economics, 12(2), 327-340.

Wood, C. (1992). The bubble economy: The Japanese economic collapse. London: Sidgwick \& Jackson.

Yamanaka, K. (2008). Japan as a country of immigration: Two decades after an influx of foreign workers. In S. Yamashita, M. Minami, D. W. Haines \& J. S. Eades (Eds.), Transnational Migration in East Asia (pp. 187-196). Osaka: National Museum of Ethnology.

Young, E. L. (1983). The society and its environment. In F. M. Bunge (Ed.), Japan: A country study (pp. 53-90). Washington, D.C.: The American University.

Zolberg, A. R. (2000). The politics of immigration policy: An externalist perspective. In N. Foner, R. G. Rumbaut \& S. J. Gold (Eds.), Immigration research for a new century: Multidisciplinary perspectives (pp. 60-68). New York: Russell Sage Foundation. 